\title{
¿DEL PERGAMINO A LA PIEDRA? \\ ¿DE LA PIEDRA AL PERGAMINO? \\ (ENTRE DIPLOMAS, OBITUARIOS Y EPITAFIOS MEDIEVALES \\ DE SAN ISIDORO DE LEÓN)
}

\begin{abstract}
ANA SUÁREZ GONZÁLEZ
Resumen: San Isidoro de León posee un extraordinario patrimonio escrito medieval: libros, diplomas e inscripciones. El presente estudio trata de documentos datados desde mediados del siglo XII hasta el primer tercio del siglo XIII, en los cuales, de una forma u otra, aparece la idea de la muerte. Las donaciones, los obituarios y los epitafios nos permitirán recorrer el camino seguido por una noticia desde el pergamino a la piedra y viceversa $y$, al mismo tiempo, utilizando los tres tipos de fuentes a la vez, acrecentar los datos de los cuales los historiadores disponen hasta el presente sobre los personajes que gozaron de importancia especial en el citado período.

XIII.

Palabras clave: Documentos; Obituarios; Epitafios; San Isidoro de León; Siglos XII-

Abstract: The Royal Collegiate church of San Isidoro owns an extraordinary legaly of medieval writings: books, documents and inscriptions. This essay deals with pieces dated in between half of the $12^{\text {h }}$ century and the first third of the $13^{\text {th }}$ century in which we cand find items related to death. Letters of donation, obituaries and epitaphs will allow us to follow the path of any given notice from the parchment up to the stone and viceversa. We can also amplify, using together the three kinds of sources, the number of items about very important characters of the period and so far belonging to historians. 13th centuries.

Keywords: Epitaphs; Letters of donation; Obituaries; San Isidoro de León; 12th-

\section{SUMARIO}

1. Objeto, tiempo y lugar.- 2. ¿Un viaje de ida y vuelta?.- 2.1. Entre pergaminos (del documento al obituario). 2.2. ¿Del pergamino a la piedra? (obituarios y epitafios). 2.3. ¿De la piedra al pergamino? (epitafios y obituarios).- 3 . De piedras y pergaminos.

${ }^{1}$ Departamento de Patrimonio Histórico-Artístico y de la Cultura Escrita, Facultad de Filosofía y Letras, Universidad de León. 2002 .

Fecha de recepción del artículo: marzo 2002. Fecha de aceptación y versión final: diciembre

«Anuario de Estudios Medievales», 33/1 (2003), pp. 365-415 .- ISSN 0066-5061.
\end{abstract}


Para algunos sólo son letras; para otros, además, mensajes. Estos últimos, más afortunados, han obtenido información interpretando caracteres y lengua. Sin embargo, también sobre los primeros ejercen los letreros en piedra su poder; las inscripciones llaman la atención de los visitantes que cada día acceden al celebérrimo Panteón de los Reyes de San Isidoro de León, pasean por la galería inferior del claustro meridional o se introducen en la iglesia. Son estos espacios cobijo privilegiado de la cultura escrita medieval, pero no los únicos en la Real Colegiata. Basta con acceder a la Biblioteca renacentista - que hoy recoge los fondos bibliográficos y documentales de la institución- para continuar el viaje a través de la escritura y de lo escrito ${ }^{2}$.

San Isidoro de León es parada obligada para cualquier interesado en la escritura latina medieval. En su recinto conviven diplomas, libros e inscripciones coetáneos, objetos escritos que permanecen en el lugar para el que se concibieron, en el que se materializaron y en el que desempeñaron $-\mathrm{y}$ desempeñan - prioritariamente su función comunicadora.

En la Real Colegiata el investigador tiene la fortuna de poder comparar diversos tipos de monumentos gráficos, para descubrir, por ejemplo, cómo un mismo artífice - miembro de la canónica - fue a la vez copista de libros, scriptor de documentos y ordinator de un epígrafe, para fijar con precisión la edad de unas piezas tomando como referencia la datación explícita de otras, para establecer las relaciones entre los signos que se ejecutaron sobre piel y los que se dispusieron en muros, bóvedas o sepulcros...

Pero, si atendiendo a la escritura las ventajas de un estudio comparativo son ya numerosas, dirigiendo el interés a lo escrito éstas se multiplican.

En lo escrito se centrará ahora nuestra propuesta, realizando un recorrido a través de los tres tipos de objetos señalados: libros, documentos e inscripciones. Teniendo en cuenta el extraordinario volumen del patrimonio gráfico isidoriano, es necesario acotar el campo de trabajo y lo hacemos tomando como base, en primer lugar, el tipo de información. Buscando temas con materialización simultánea libraria, documental y epigráfica, llegamos a los mensajes funerarios.

\footnotetext{
${ }^{2}$ Viaje posible, en buena medida, por la colaboración de D. Antonio Viñayo González, abadprior de la Real Colegiata, que siempre facilita la labor a cuantos elegimos San Isidoro de León como centro de trabajos sobre la escritura y lo escrito.

*La redacción de este artículo ha concluido en diciembre de 2001.

*Anuario de Estudios Medievales*, 33/1 (2003), pp. 365-415 .- ISSN 0066-5061
} 
En San Isidoro de León las noticias relacionadas de algún modo con la muerte - unas veces como realidad presentida y futura, otras como hecho ya consumado - se plasman en un importante número de monumentos gráficos $^{3}$. A primera vista, la información parece viajar de una pieza a otra, de pergamino a piedra y de piedra a pergamino. Un documento puede recoger el nombre de generosos donantes preocupados por asegurarse el recuerdo y la oración de los canónigos y, a veces, también un espacio para su sepultura en el recinto de la Real Colegiata, nombres que tal vez figuran entre los inscritos en un obituario de la canónica y, conformados mediante caracteres incisos, destacarse en algunos de los muros del claustro meridional.

Son iguales los nombres, se halla presente siempre - de un modo $u$ otro- la realidad de la muerte ${ }^{4}$, pero ¿es idéntica la noticia que se plasma en piedra y en pergamino? o, dicho de otro modo, ¿coincide la finalidad del mensaje? ¿se repite exactamente la información? ¿se copia?

A estas y a otras preguntas intentaremos responder a lo largo del estudio que ahora se inicia, pero, además, el recorrido propuesto permitirá poner de relieve una vez más, con ejemplos concretos, las ventajas de contar con tres tipos de monumentos gráficos relativos a un mismo hecho para conseguir algunas de las cualidades exigidas a la buena información: exactitud, precisión e integridad ${ }^{5}$.

\section{OBJETO, TIEMPO Y LUGAR}

Son diplomas, obituarios y epitafios los tipos específicos de objetos escritos que nos interesan. Pero, decíamos antes, sólo aquéllos que forman

\footnotetext{
${ }^{3}$ No es extraño: "Hay que insistir en que la muerte, por su misma ineluctabilidad, ha sido objeto de permanente tratamiento por las distintas sociedades. Ningún otro tema -trabajo, amor, guerra, pobreza, etc., objeto de renovado interés por parte de las distintas ciencias sociales- pese a afectar a las distintas capas sociales, puede tener una proyección tan general y, por tanto, ser capaz de generar un interés tan acusado" (E. MITRE, El sentido medieval de la muerte. Reflexiones desde el prisma del siglo XX, "Anuario de Estudios Medievales", 16 [1986], p. 621).

${ }^{4} \mathrm{O}$, para ser más exactos, de la "muerte cristiana", que conlleva la necesidad o el deseo del creyente de garantizarse un recuerdo y una plegaria "permanente y repetida" (cf. P.A. FÉVRIER, La mort chrétienne, "Segni e riti nella Chiesa altomedievale occidentale (Settimane di studio del centro italiano di studi sull'alto medioevo XXXIII)", II, Spoleto, 1987, pp. 883 y 939.

${ }^{5} \mathrm{Cf}$. Y. RENOUARD, Information et transmission des nouvelles, "L'Histoire et ses méthodes", Paris, 1961, pp. 95-142, especialmente las pp. 134-135.

«Anuario de Estudios Medievales*, 33/1 (2003), pp. 365-415 .- ISSN 0066-5061.
} 
parte del patrimonio escrito de la Real Colegiata leonesa ${ }^{6}$ y que, precisión que incorporamos ahora, pueden datarse -atendiendo a su materialización- ${ }^{7}$ entre mediados del siglo XII y el primer cuarto del siglo XIII ${ }^{8}$. El periodo elegido es especialmente rico en producción escrita libraria, diplomática y epigráfica debido a varios factores. Desde que, a partir de $1148^{9}$, se establecen en San Isidoro de León canónigos regulares de san Agustín, hasta la segunda década del siglo XIII, se verifica un crecimiento paulatino de la comunidad $^{10}$. Otro factor dinamizador lo constituye la vinculación del centro isidoriano a la monarquía leonesa. Alfonso VII y su hermana Sancha, Fernando II y Alfonso IX junto con sus esposas realizan una labor de mecenazgo que se plasma también en el campo de la cultura escrita. Por último, debemos señalar un aspecto fundamental para el desarrollo de labores escriptorias sobre materiales como el pergamino y la piedra: la prosperidad económica. Hasta finales del siglo XII, San Isidoro de León incrementa considerablemente su patrimonio mueble e inmueble con significativas adquisiciones fruto en muchos casos de generosas donaciones.

Situados ya en tiempo y lugar, centrémonos ahora en el objeto o, mejor dicho, en los objetos de nuestra aproximación.

${ }^{6}$ Todas las piezas seleccionadas para el estudio se custodian hoy en el recinto de la Real Colegiata, salvo un fragmento depositado en el Museo de León que contiene parte del epitafio de Sancho el Mayor de Navarra. Otro fragmento del mismo sepulcro permanece en el claustro isidoriano.

${ }^{7}$ Por esta razón también introducimos en el estudio monumentos gráficos con información referida a los siglos X y XI, momentos muy anteriores a la implantación de la canónica regular en San Isidoro, pero configurados materialmente uno o dos siglos después, según los casos.

${ }^{8}$ Para delimitar el periodo hemos preferido atender a la historia de la comunidad de canónigos regulares que se instala en San Isidoro que recurrir a acontecimientos históricos de mayor relieve. Por esta razón no prolongamos el marco temporal hasta 1230, año en el que acaeció el fallecimiento de Alfonso IX, pero que no tuvo especial relevancia en la evolución interna de la canónica, autora de los objetos escritos que nos interesan.

${ }^{9}$ En el diploma ASIL 146 se recoge la implantación de una canónica regular en el centro isidoriano.

${ }^{10}$ Es este el periodo del gobierno prioral de Pedro Arias y Martín Muñoz, de los abadiatos completos de Menendo, Martino I, Facundo, Martino II, Rodrigo, García y Juan y el inicio del abadiazgo de Martino III (cf. A. VIÑAY YO GONZÁLEZ, Abadía de San Isidoro de León, fundación y primera comunidad de canónigos regulares de San Agustín (1148-1167), "Monjes y monasterios españoles", II, San Lorenzo del Escorial, 1995, pp.745-775 y A. SUÁREZ GoNZÁLEZ, Aproximación a la comunidad de San Isidoro de León entre 1156 y 1248 (estudio cuantitativo y cualitativo), "Estudios Humanísticos", 14 (1992), pp. 145-172). A partir de la segunda década del siglo XIII las fuentes indican una tendencia al estancamiento en el número de canónigos y una evolución hacia el retroceso. También se observan problemas en el gobierno de la comunidad, dificultades que motivaron antes de 1221 la dimisión del citado abad Garsias. 
Comencemos el recorrido por la biblioteca-archivo de San Isidoro y detengámonos en los diplomas. El fondo documental de la Real Colegiata correspondiente al período que nos interesa es muy rico. Se compone de casi dos centenares de piezas diplomáticas originales en pergamino con escritura carolina evolucionada y pregótica, a las que hay que añadir algunas copias especialmente significativas, varias de las cuales pueden datarse también - tomando como base sus caracteres gráficos- en el marco temporal elegido para nuestra aproximación ${ }^{11}$. Obra de numerosísimas manos, algunas de las cuales participaron en la confección de códices, los documentos son muy heterogéneos también en lo que atañe a otros caracteres externos: calidad de la membrana empleada como soporte, dimensiones, pautado, color de las tintas, etc. Atendiendo a su contenido y a la figura de sus autores, el Catálogo del archivo isidoriano, realizado por el abad J. Pérez Llamazares, diferencia cuatro grupos: diplomas "pontificios", "eclesiásticos", "reales" y "particulares"12. Teniendo en cuenta su autoría y objetivos, excluimos de la presente aproximación los documentos pertenecientes a los dos primeros grupos. Por lo que se refiere a los denominados "documentos reales", debemos llamar la atención sobre su gran peso en el marco temporal elegido para este recorrido. En torno a medio centenar de instrumenta - privilegios, cartas, mandatason testigos de la generosidad de Alfonso VII, Fernando II y Alfonso IX, junto a sus familiares, hacia la canónica isidoriana. Sin embargo, tampoco constituyen éstos la base principal de nuestro estudio, sino los documentos considerados "particulares". Aproximadamente un centenar de piezas diplomáticas se insertan en el periodo objeto de análisis, de las cuales una veintena no tienen en principio relación directa explícita con la canónica, puesto que ésta no figura ni en su intitulación ni en su directio. Los abades isidorianos intitulan poco más de una decena de documentos - cartas de permuta, de fuero, de venta, avenencias y concordias-y, a su vez, la Real Colegiata es destinataria de casi medio centenar de diplomas de transmisión de bienes: cartas de venta, $y$, muy especialmente, según se deduce de su

\footnotetext{
${ }^{11}$ Para conocer el volumen de documentación y su contenido, véanse J. PÉREZ LLAMAZARES, Catálogo de los códices y documentos de la Real Colegiata de San Isidoro de León, León, 1923, pp.89-179, ID., Catálogo de los incunables y libros antiguos, raros y curiosos de la Real Colegiata de San Isidoro de León, Madrid, 1943, pp.130-131, E. MARTín LóPEZ, Patrimonio cultural de San Isidoro de León. A. Serie documental. I/I. Documentos de los siglos X-XIII. Colección diplomática, León, 1995, pp.69-252 (n $\left.{ }^{\mathrm{os}} .43-223\right)$ y A. SUÁREZ GONZÁLEZ, Patrimonio cultural de San Isidoro de León. B. Serie bibliográfica. II. Los códices III.1, III. 2, III.3, 4 y 5 (Biblia, Liber capituli, Misal), León, 1997, pp.443-444 (en adelante, Patrimonio cultural II).

${ }^{12}$ Cf. J. PÉrez LlamazARES, Catálogo de los códices, pp. 89-179
} 
número, cartas de donación. Precisamente estas últimas, más de treinta, son las que podemos considerar esenciales para el recorrido propuesto a través del patrimonio escrito isidoriano relacionado con la muerte.

Continuamos la aproximación a los objetos de pergamino. Es el momento de hacer referencia a los obituarios, registros en los que, tomando como base el calendario, los canónigos isidorianos inscribieron los nombres de las personas e instituciones -otras canónicas, comunidades monásticasencomendadas a sus plegarias ${ }^{13}$. Son tres las piezas que debemos tener en cuenta ${ }^{14}$. Las dos primeras se localizan en un mismo volumen, el ms.IV de la biblioteca isidoriana, Liber Capituli ${ }^{15}$ facticio, en pergamino, compuesto por cuatro sectores originarios de mediados del siglo XII. El primero de los obituarios - lo designaremos Obituario 1- se dispone en el sector A del ejemplar (concretamente en los fols. 1v-7r) y el segundo - Obituario 2- en el sector C (fols. 38r-57v). El tercer obituario (Obituario 3) se halla, sorprendentemente, en el Códice III.2 (fols. 182-187). Constituye el último sector de un volumen facticio cuyo núcleo forma parte de la conocidísima Biblia románica isidoriana.

Las noticias necrológicas que conforman el Obituario 1 son resultado de numerosas intervenciones. Tomando como base la escritura y algunas fechas explícitas, podemos determinar que las adiciones se inician a mediados del siglo XII y concluyen a comienzos de la centuria siguiente. No se constata

\footnotetext{
${ }^{13}$ La definición se basa en la que propone M. DyKmans, Les obituaires romains. Une définition suivie d'une vue d'ensemble, "Studi Medievali", 19 (1978), p. 591. En la misma línea se halla la que ofrece A. PrATESI, Obituario, "Enciclopedia Cattolica", IX, Città del Vaticano, 1952, col. 20. Para denominar a este tipo de textos se han empleado dos vocablos -Necrologio y Obituario-, utilizados no pocas veces como sinónimos por los investigadores. Sin embargo, dos estudiosos se han ocupado especialmente de la diferenciación entre ambos libros, atendiendo a diversos criterios: N. HUYGHEBAERT, Les documents nécrologiques, Turnhout, 1972, p.35 y J.L. LEMAÎTRE, Les documents nécrologiques, Turnhout, 1985, p. 11. Sobre el concepto de obituario y los problemas de nomenclatura, cf. Patrimonio cultural II, pp. 305-306 y 427-428.

${ }^{14} \mathrm{La}$ Real Colegiata cuenta con otros dos obituarios más jóvenes, ambos en el Códice LXXV, el primero datable en el siglo XVI y el segundo en el XVIII. Asimismo, varias relaciones de canónigos difuntos se hallan en manuscritos históricos de la institución datables en los siglos XVI y XVII. Por lo que se refiere a los tres obituarios con origen en la Edad Media, estamos preparando su edición.

${ }^{15}$ Denominación que se ajusta a su estructura, su contenido y su utilización como libro imprescindible para el Officium Capituli tras Prima. Se recoge una escueta definición de este tipo de libro en VV.AA, Livre du chapitre (Glossaire), "Le livre au Moyen Âge", Paris, 1988, p. 241 y J. WOLlASCH, Les obituaires, témoins de la vie clunisienne, "Cahiers de Civilisation Médiévale", 2 (1979), p. 144. Sin embargo, el Códice IV aparece catalogado como Martirologio y Necrologio (J. Pérez llamazares, Catálogo de los códices, p. 24). El análisis de este ejemplar facticio y de sus dos obituarios en A. SuÁreZ GonZÁleZ, Patrimonio cultural II, pp. 323-455.
} 
explícitamente la defunción de ningún canónigo isidoriano pero sí se consigna el óbito de familiares.

El Obituario $2^{16}$ es también muy heterogéneo gráficamente y, a diferencia de lo advertido en el Obituario 1, la mayor parte de los asientos se refieren a miembros de la comunidad isidoriana - canónigos- o a personas muy vinculadas ella: conversos, socii, etc. Las expresiones canonicus Sancti Ysidori o conuersus/a huius ecclesie se prodigan en sus páginas. En la mayoría de los casos, la escritura de la adición coincide con la fecha, explícita o no, de la defunción que se consigna. Creemos que este obituario se elaboró en torno a 1150 y se incorporaron numerosas noticias hasta 1270 . Podemos tomar la última fecha citada como año de conclusión temporal de este libro vivo, que no vuelve a registrar asientos hasta el siglo XVI.

Estrechamente relacionado con el anterior se halla en Obituario 3, el de origen más tardío (c.1212), de vida útil más breve y el más homogéneo gráficamente ${ }^{17}$. La mano que copió la totalidad del texto originario resulta especialmente familiar: es el artífice principal del Códice VI de la biblioteca isidoriana, realizó adiciones en otros libros y escrituró varios diplomas custodiados en el archivo ${ }^{18}$. El libro necrológico ha llegado a nosotros gravemente mutilado ${ }^{19}$, pero, aun así, es pieza de gran interés. Analizando el texto de las noticias necrológicas originarias, se deduce que su fuente básica es el que hemos llamado Obituario $2^{20}$. Por lo tanto, también hallamos en él los nombres de canónigos de San Isidoro, conversos, sacerdotes ajenos al cenobio, obispos, milites, miembros de la familia real, comunidades monásticas, etc. La escritura de los asientos necrológicos comprendidos en el periodo objeto de estudio es carolina evolucionada y pregótica, unas veces libraria y otras documental.

\footnotetext{
${ }^{16}$ Este obituario está levemente mutilado. Ha desaparecido uno de los folios orginarios y, debido a ello, faltan las memorias desde el día 31 de mayo al 17 de junio, ambos inclusive.

${ }^{17}$ Véase la justificación de esta datación y el análisis - externo e interno- de la pieza en Patrimonio cultural II, pp. 104-108.

${ }^{18}$ Cf. Patrimonio cultural II, pp. 104-108 y 237-243 y A. SUÁREZ GoNZÁLEZ, Patrimonio cultural de San Isidoro de León. B. Serie bibliográfica. III. Los códices VI-X.2, León, 2001, pp.19-36 y 78-87. (En adelante, Patrimonio cultural III).

${ }^{19}$ Se conservan sólo las noticias correspondientes a los meses de enero, febrero, junio y julio completos y parte de las relativas a los meses de marzo, mayo y agosto.

${ }^{20}$ Lógicamente el artífice sólo conoce y copia las noticias de éste datables desde mediados del siglo XII hasta, aproximadamente, 1212 (fecha de una de las adiciones del Obituario 3, en el f.186r del Códice III.2).

«Anuario de Estudios Medievales», 33/1 (2003), pp. 365-415 .- ISSN 0066-5061.
} 
De los tres tipos de objetos escritos que ahora nos incumben, son, sin duda, los epitafios - o inscripciones funerarias ${ }^{21}$ - los que mayores problemas presentan.

Se localizan las inscripciones que tendremos en cuenta en el Panteón de los Reyes, en el claustro meridional - adyacente a la iglesia- y en una capilla abierta en el muro oeste del mismo. En el primer recinto hallamos los epitafios correspondientes a miembros de la familia real, sobre cubiertas de sarcófagos. En el claustro propiamente dicho los caracteres se asoman en los muros y en basas; algunos, desplazadas las piezas de su lugar originario, aparecen en cubiertas de sepulcros mutiladas y en sillares ahora aislados depositados en el suelo o apoyados en la pared de la galería este. Los epígrafes del claustro son intitulados por personajes de los que rara vez se especifica condición, salvo cuando se trata de fragmentos que originariamente formaron parte del conjunto sito en el panteón real. El tercer espacio -la mayor de las estancias abiertas en el muro occidental del claustro- alberga los letreros protagonizados por prelados de la comunidad isidoriana ${ }^{22}$.

Un primer problema lo plantea la conservación y la supervivencia de las inscripciones. Si bien pueden considerarse numerosos los epígrafes funerarios que permanecen en San Isidoro de León ${ }^{23}$, y buena parte de ellos corresponden al periodo que nos interesa, han desaparecido muchos de los que

\footnotetext{
${ }^{21}$ A propósito de este tipo de inscripciones y su evolución, R. FAVREAU, Épigraphie médiévale, Turnhout, 1997, pp. 291-311.

${ }^{22}$ Trasladadas estas sepulturas de lugar [cf. J. LóPEZ CASTRILLÓN e I. REDONDO, Arqueología cristiana. Sarcófagos recién hallados en la colegiata de San Isidoro de León, "Boletín de la Real Academia de la Historia", 8 (1886), pp. 351-358].

${ }^{23} \mathrm{Las}$ inscripciones isidorianas se hallan actualmente en proceso de estudio y edición por parte del profesor V. García Lobo como parte del volumen correspondiente a la provincia de León en el Corpus Inscriptionum Hispaniae Mediaevalium. Sin embargo, disponemos ya de una primera aproximación al fondo epigráfico de la Real Colegiata realizada por el mismo investigador (Las inscripciones medievales de San Isidoro de León. Un ensayo de Paleografía epigráfica medieval, "Santo Martino de León", León, 1987, pp. 371-398). Señala V. García Lobo: "la colección epigráfica medieval de San Isidoro está formada por ciento ocho inscripciones, de las cuales se conservan actualmente ochenta y ocho sobre materiales de la más variada naturaleza: piedras de distintas clases, metales diversos, tejidos, maderas y pinturas". Asimismo, lleva a cabo una clasificación (Ibídem, pp. 384-388). En un trabajo posterior, realizado en colaboración, precisa el número de epitafios -treinta y uno- y señala que predominan los sepulcrales (cf. V. GARCíA LOBO y E. MARTín LÓPEZ, La publicidad y el Císter, "Monjes y monasterios. El Císter en el medievo de Castilla y León", Valladolid, 1998, p. 48). Por lo que se refiere a los aspectos genéticos y la tradición de los epígrafes, habremos de conformarnos con las observaciones publicadas por el Dr. García Lobo hasta la fecha, teniendo en cuenta que las afirmaciones se verán sin duda matizadas y ampliadas cuando finalice su estudio y edicion.
} 
en su día cobijó la Real Colegiata ${ }^{24}$. Por otra parte, varios de los epitafios que aún permanecen en el recinto isidoriano se hallan muy deteriorados 0 reducidos a fragmentos. La aproximación a este patrimonio epigráfico perdido únicamente podemos realizarla a través de copias literarias, acercamiento parcial, pues sólo los letreros considerados más relevantes por su especial significación histórica fueron reproducidos en diversos manuscritos de los siglos XVI y XVII custodiados en la biblioteca isidoriana (códices 91-94) ${ }^{25}$ y editados por Ambrosio de Morales, Lobera, Sandoval, Yepes, Manzano, Flórez o Risco entre otros eruditos ${ }^{26}$.

El segundo problema lo constituye la tradición de los epitafios supervivientes. Como señala el profesor V. García Lobo

\footnotetext{
${ }^{24}$ Los efectos de la llegada del ejército francés a San Isidoro a principios del siglo XIX y sus destrozos en el panteón de reyes fueron nefastos para las inscripciones, como señala M. Gómez Moreno: "Entonces todo fue deshecho: se profanaron las tumbas y se esparcieron las piedras" (Catálogo monumental de la provincia de León (1906-1908), Madrid, 1925, p. 213) "Posteriormente, se hallaron, en un rincón de la Colegiata, otros fragmentos de las tumbas reales, entre ellos dos en los que se reconocen palabras de los epitafios de Xemena, mujer de Bermudo III, y de Sancho el Mayor de Navarra, con algo de las figuras yacentes de ambos, grabadas conforme a las otras" (Ibidem, p. 214).

${ }^{25}$ Son cuatro volúmenes misceláneos que contienen textos muy importantes para la reconstrucción de la historia de San Isidoro de León. La relación más completa de epitafios -y la más fiable-, aunque en ningún caso puede considerarse exhaustiva, se localiza en el Códice XCI, fols. 83-89, precedida del siguiente epígrafe: "Catálogo de los Reyes y Reynas, infantes e infantas, condes y caballeros de sangre real que están sepultados en la capilla real de Santa Catherina desta yglesia de Sanct Ysidro" (fol. 83 r). Un índice posterior -de otra mano-, incorporado al inicio del ejemplar, advierte a propósito del texto que ahora nos ocupa: "este cathálogo fue ymbiado a su Magestad Cathólica del Rey Don Phelipe por el Doctor Ambrosio de Morales en el año 1572" (fol. 1 r). En el Códice XCII los letreros se copiaron en los fols. 31-39 y en el Códice XCIII en los fols. 28-31. En el Códice XCIV, a diferencia de los anteriores, los epitafios no figuran en una relación, sino que se intercalan a lo largo del texto histórico cuando se alude al personaje en cuestión.

${ }^{26}$ De las relaciones que ofrecen J.I. GIL PuLIDo, Los epitafios del panteón de los reyes de San Isidoro de León (999-1159). Problemas históricos, "Santo Martino de León", León, 1987, p. 402, nota 6 y J.M. GARCía LOBO, Inscripciones medievales desaparecidas de San Isidoro de León, "Santo Martino de León", León, 1987, pp.415-419, seleccionamos sólo las obras que citaremos a lo largo de este estudio: A. DE LOBERA, Historia de las grandezas de la muy antigua y insigne ciudad y Iglesia de León, Valladolid, 1596; J. MANZANO, Vida y portentosos milagros de el glorioso san Isidro, arzobispo de Sevilla, y egregio doctor, y maestro de las Españas, con una breve descripción de su magnífico Templo y Real Casa de el mismo Señor S. Isidro, en la muy noble Ciudad de León, Salamanca, 1732; A. DE MORALES, Viage por orden del rey D. Phelipe II a los reynos de León, y Galicia, y principado de Asturias, Madrid, 1765 , M. RisCo, Iglesia de León y monasterios antiguos y modernos de la misma ciudad, Madrid, 1792; P. DE SANDOVAL, Historia de los Reyes de Castilla y de León, don Fernando el Magno, primero de este nombre, infante de Navarra. Don Sancho, que murió sobre Zamora. Don Alonso, sexto de este nombre. Doña Urraka, hija de don Alonso sexto. Don Alonso séptimo, emperador de las Españas, Pamplona, 1615 y A. DE YEPES, Crónica general de la Orden de San Benito (ed. de J. Pérez de Urbel), II, Madrid, 1960.
} 
Es difícil en el estado actual de la Epigrafía medieval establecer unos criterios seguros para distinguir con acierto la tradición epigráfica.

Para hacer referencia a la tradición, es preciso diferenciar entre los dos tipos de inscripciones funerarias que individualiza V. García Lobo atendiendo a su contenido específico y formulario: las "sepulcrales" y las "necrológicas"27. "Correspondientes las primeras a lugares y fechas de enterramiento" -advertía A. Durán Gudiol ${ }^{28}$-, "recogen -completa V. García Lobo- simultáneamente la noticia de la muerte y de la sepultura del difunto"29. Se caracterizan los epitaphia sepulcralia por la inclusión de expresiones como "hic requiescit" "hic quiescit", "requiescit in...", "hic iacet" ${ }^{\prime 30}$. Los epitafios necrológicos se inician con el notificativo obiit $t^{31}$ y "dan cuenta solamente de la muerte - no de la sepultura- del difunto"32.

Así, por lo que se refiere a las inscripciones isidorianas de carácter funerario, en opinión de V. García Lobo, cabe hablar de originales, copias y renovationes ${ }^{33}$ :

las necrológicas deben ser calificadas de copias. Las sepulcrales, por su parte, presentan una casuística más compleja. Las trazadas sobre lápidas parietales (...) son copias literales posteriores a la fecha del fallecimiento. Las trazadas sobre las cubiertas de los sepulcros, hemos de confesar que hasta que no entramos en contacto con las inscripciones de San Isidoro, las

${ }^{27}$ Es la clasificación realizada por expertos en inscripciones peninsulares, pero no podemos olvidar la existencia de otras propuestas al respecto. R. Favreau se detiene en las modalidades de epitafios de los siglos XI y XII y, atendiendo al formulario y al estilo, diferencia tres tipos. El más sencillo, según este investigador, es el epitafio que comienza con el verbo que alude a la sepultura, seguido del nombre del difunto $\mathrm{y}$, a menudo, su función, formulario que puede completarse con la data y la solicitud de una plegaria (cf. O.c., p. 297). En el segundo tipo se hallarían las inscripciones análogas en formulario a las anotaciones de obituario (ibidem, pp. 298300) y el tercer tipo de epitafio - a su juicio, el más extendido - es el versificado (pp. 301-302).

${ }^{28} \mathrm{~A}$. DURAN Gudiol, Las inscripciones medievales de la provincia de Huesca, "Estudios de Edad Media de la Corona de Aragón", 8 (1967), p. 47.

${ }^{29} \mathrm{~V}$. GARCía LoBo, Las inscripciones, p. 386.

${ }^{30}$ Expresiones que, como hemos constatado, pueden omitirse o alterarse cuando el epígrafe se redacta en verso.

${ }^{31}$ A. DuRAN Gudiol, O.c., p. 47.

${ }^{32} \mathrm{~V}$. GARCÍA LOBO, Las inscripciones, p. 386.

${ }^{33} \mathrm{Al}$ admitir la existencia de renovationes, las aseveraciones de V. García Lobo corroborarían en parte las afirmaciones de M. Gómez Moreno cuando señala que se verificó "una renovación general de los sepulcros después de concluida la iglesia" (Catálogo monumental, p. 214). También apunta el profesor García Lobo la existencia de epitafios falsos en el conjunto epigráfico isidoriano (Las inscripciones, p. 388). 


\begin{abstract}
teníamos como indefectiblemente originales. Al comprobar que entre los epígrafes de San Isidoro hay inscripciones sepulcrales ejecutadas en letra del siglo XIII, cuyos titulares o protagonistas habían fallecido en el siglo $\mathrm{X}$ o en el XI, no pudimos menos de reconsiderar nuestra postura y tratar de encontrar una solución a esta aparente contradicción (...). Evidentemente, aquellas inscripciones habían sido renovadas. A este tipo de inscripciones, cuyos textos han sido redactados sobre la base de otro texto anterior que conservan lo esencial - notificación, intitulación y data- entendemos que debemos calificarlas, por analogía con el fenómeno diplomático, de renovationes. (...) Las renovaciones requieren a nuestro juicio una crítica especial ya que en ellas puede darse con mayor facilidad la falsificación. No obstante, creemos que este tipo de tradición - la renovatio - no debe ser frecuente. Por ello entendemos que puede manifestarse como principio general que las inscripciones sepulcrales que se mantienen sobre las cubiertas de los sepulcros son originales, pero atentos siempre a la posibilidad de encontrarnos con una renovatio ${ }^{34}$.
\end{abstract}

Hemos de señalar, sin embargo, que el grupo de epitafios en los que centraremos nuestra atención correspondería únicamente al primer tipo mencionado (epitaphia sepulcralia). En unos casos porque aparece claramente especificada en los letreros la noticia de la sepultura -mediante notificativos explícitos- y en otros porque, ausente de su tenor cualquier alusión al enterramiento ${ }^{35}$, se trata de inscripciones grabadas en los sepulcros de los personajes a los que se refieren. Todos estos epitaphia son latinos y, en lo que atañe a su estilo, unos se redactaron en prosa y otros son rítmicos o versifica$\operatorname{dos}^{36}$. Por lo que se refiere a su materialidad, se componen de caracteres carolinos, pregóticos y góticos primitivos grabados en piedra (mármol, sillares y sillarejos de caliza, etc.).

\footnotetext{
${ }^{34} \mathrm{~V}$. GARCÍA LOBO, Las inscripciones, pp.387-388.
}

${ }^{35}$ Incluso, puede aparecer únicamente el notificativo obiit. Sirva de ejemplo el que podemos denominar primer epitafio de Sancha, hermana de Alfonso VII: su formulario se ajusta a un epitafio necrológico, pero se dispone en la cabecera del sepulcro de la infanta.

${ }^{36} \mathrm{Al}$ respecto de los epitafios versificados en los siglos XI y XII señala R. Favreau que son los más cuidados y frecuentemente asociados a príncipes, obispos y abades (cf. R. FAVREAU, O.c., p.301). En San Isidoro de León corresponden a mujeres de la familia real y prelados de la canónica. En referencia a los epitafios del Panteón Real, ya advertía Ambrosio de Morales: "Las sepulturas, que están en dos órdenes juntas unas con otras, tienen todas sus epitafios en latín, en verso algunas, y otras en prosa, y otras en verso y prosa" (A. DE MORALES, O.c., p. 42), la misma reflexión en ASIL, Códice XCI, fol. 83 v. Sin embargo, como demuestran algunos epígrafes supervivientes, son letreros diferentes - uno en prosa y otro en verso- ejecutados en momentos distintos sobre la misma supeficie. Volveremos sobre esta cuestión más adelante.

«Anuario de Estudios Medievales», 33/1 (2003), pp. 365-415 .- ISSN 0066-5061. 


\section{2. ¿UN VIAJE DE IDA Y VUELTA?}

Hasta ahora hemos abordado los tres tipos de objetos escritos aisladamente, es ya momento de establecer entre ellos las oportunas relaciones, precisando qué comparten además de la edad y su custodia en el mismo centro eclesiástico ${ }^{37}$.

\subsection{Entre pergaminos (del documento al obituario)}

Los expertos en textos necrológicos medievales consideran fuera de toda duda la relación genética entre ciertos diplomas que recogen donaciones dirigidas a una determinada comunidad o institución religiosa y los asientos en sus obituarios, sobre todo cuando en la carta se hace referencia a su destino específico para la celebración de aniversarios del otorgante. Esta estrechísima vinculación se observa claramente también en el ámbito isidoriano: la incorporación de un determinado nombre en el libro necrológico se ve en muchos casos precedida - y justificada - por una acción garantizada documentalmente. No queremos decir con ello que sea ésta la única vía para explicar la presencia de un determinado nombre en este tipo de libro mitad administrativo mitad litúrgico: en los obituarios isidorianos tienen gran peso los miembros de la canónica y sus familiares, así como otras personas y comunidades monásticas vinculadas espiritualmente a la colegiata mediante compromisos de sufragios y actas de hermandad ${ }^{38}$.

Sin embargo, siendo nuestro objetivo seguir el camino que parte de un diploma y se detiene en el obituario, nos ocuparemos sólo de los asientos

\footnotetext{
${ }^{37}$ En las transcripciones de los textos respetaremos la grafía original de los términos aunque sea defectuosa, pero, para facilitar la interpretación, puntuaremos conforme al criterio actual. Asimismo, desarrollaremos las palabras abreviadas, indicando las letras suplidas en la transcripción diferenciándolas mediante su realización en cursivas. Las lecturas dudosas las señalaremos con (?), las letras o palabras ilegibles por tachaduras o deterioro del soporte se sustituirán por [...] y a los términos con errores graves se pospondrá (sic). Existen normas específicas para la edición de textos epigráficos (cf. V. GARCíA LoBO, Las inscripciones, p.389); sin embargo, con el fin de diferenciar gráficamente a lo largo de este artículo los textos procedentes de diplomas y obituarios de los recogidos en epígrafes supervivientes, reproduciremos estos últimos íntegramente en versalitas.

${ }^{38} \mathrm{De}$ hecho, algunas fuentes para las adiciones - compromisos de sufragios, actas de hermandad con otras comunidades monásticas - forman parte del propio Códice IV. El Sector A del volumen recoge la noticia de la fraternidad establecida entre el abad isidoriano Facundus, junto a su comunidad, y el abad de Ripoll -Raimundus - y algunos de sus monjes (fol. $8 \mathrm{v} \mathrm{del}$ manuscrito). Se acuerda celebrar officium annuatim quarto die post festum omnium sanctorum y en el que denominaremos Obituario 2 se constata el 4 de noviembre (fol. 54 v): Eodem die commemoracio monachorum riuipollensis ecclesie.
} 
necrológicos relacionados directamente con un documento de transmisión de bienes.

En efecto, como señalábamos antes, la donación realizada por un particular con el fin de garantizar la celebración de aniversarios justifica la incorporación del nombre del otorgante, una vez fallecido, en alguno de los libros necrológicos utilizados por los canónigos. Son especialmente significativos al respecto los obituarios 2 y 3 . Sin embargo, sólo ocasionalmente reflejan de modo explícito algunos de sus asientos la dotación que originó la adición de un nombre. La escasa presencia de apuntes contables tal vez se deba al uso litúrgico de un libro de capítulo. Los ejemplos son, no obstante, muy reveladores. La noticia de la defunción se acompaña de un apunte de índole administrativa - notas que reflejan una donación en especie o en metálicodando lugar a adiciones como la siguiente:

Obiit famulus Dei Ysidorus Iohannis qui reliquit nobis pro suo anniuersario quasdam donmos (sic) in rua noua ${ }^{39}$.

Son aún menos frecuentes, pero igualmente significativas, las referencias a entregas que revierten en los miembros de la canónica mediante distribuciones:

et Petrus del Pin, in cuius anniuersario operarius IIII morabetinos nobis persoluere debet ${ }^{40}$.

Las coincidencias entre nnmbres contenidos en las páginas de ambos libros y los autores de donaciones destinadas a la canónica isidoriana son numerosas. Es el caso, por ejemplo, de Nazarenus Martini que el 3 de agosto de 1186 entrega a San Isidoro de León heredades en Valsemana ${ }^{41}$. D. Facundo, abad de la canónica, agradece el gesto del benefactor con el siguiente compromiso:

in recompensatione huius helemosine ad obitum uestrum unusquisque nostrum uobis promittimus duo missarum sacrificia pro anima uestra

${ }^{39}$ Obituario 3, Códice III.2, fol. 183 r.

${ }^{40}$ Obituario 3, Códice III.2, fol. 183 v.

${ }^{41}$ ASIL 330 y ASIL 331, dos ejemplares de una carta partida. 
decantaturos et annuatim in die anniuersarii uestri plenum officium defunctorum completuros ${ }^{42}$. anotación

En el Obituario 2, el 7 de noviembre ${ }^{43}$, puede leerse la siguiente

Obiit famulus Dei Dompnus Nazarenus.

También es significativa la carta de Toda Núñez, dama que, en 1223, lleva a cabo junto a sus hijos, una generosa donación a la comunidad isidoriana

- pro remedio anime mee et pro anniuersario meo annuati $m$ celebrando $\mathrm{d}^{44}$

razón que explica su incorporación al Obituario 2, el 9 de abril ${ }^{45}$ :

Obiit famula Dei dompna Tota Nunni que dedit nobis quantum habebat in Uegas pro suo anniuersario.

Fácil resulta, asimismo, relacionar las siguientes anotaciones en el Obituario 2:

Obiit famulus Dei Aprilis, milex, canonicus Sancti Ysidori ${ }^{46}$.

Obiit famula Dei domna Maria, coniux domni Aprilis canonici Sancti Ysidori ${ }^{47}$.

con el siguiente texto extraído del diploma ASIL 305, fechado el 17 de marzo de 1164 - "in claustro beati Ysidori"- e intitulado por el mismo magnate y su esposa:

... Ego Aprilis et uxor mea domna Maria (...) offerimus nos Deo omnipotenti et beato Ysidoro confessori eius atque orationibus et beneficiis canonico-

\footnotetext{
${ }^{42}$ Texto tomado de ASIL 330. En ASIL 331: "in recompensatione huius helemosine ad obitum uestrum unusquisque nostrum uobis promittimus duo missarum sacrificia pro anima uestra decantaturos $e t$ annuatim in die anniuersarii uestri plenum officium defunctorum completuros".

${ }^{43}$ VII idus nouembris (Códice IV, fol. $54 \mathrm{v}$ ).

${ }^{44}$ Texto procedente de ASIL 366.

${ }^{45} \mathrm{~V}$ idus aprilis (Códice IV, fol. $43 \mathrm{r}$ ).

${ }^{46} \mathrm{En}$ II kalendas aprilis (Códice IV, fol. $42 \mathrm{v}$ ).

${ }^{47}$ El XIIII kalendas maii (Códice IV, fol. 43 v).

«Anuario de Estudios Medievales», 33/1 (2003), pp. 365-415 .- ISSN 0066-5061
} 
rum ibidem in Dei seruicio conmorantium, concedimus etiam eidem sancto loco ad sepeliendum corpora nostra. Ego autem Menendus tunc abbas eiusdem loci et totus conuentus recipimus uos in canonicos et socios nostros tam in uita quam in morte sicut unum ex nobis in orationibus in ieiuniis et elemosinis et in cunctis beneficiis nostris. Addimus etiam et stabilimus in caritate quod post mortem uestram in anniuersario uestro pro unoquoque uestro tam nos quam successores nostri unam quarentenam celebremus per singulos annos usque in perpetuum in memoriam autem huius beneficii ${ }^{48}$.

A los nombres citados podríamos añadir varios más de los recogidos en los obituarios ${ }^{49}$ : Velascus Ennici ${ }^{50}$, Iohannes Romani ${ }^{51}$, Garssia Ramiri ${ }^{52}$, Pelagius Iohannis $^{53}$, Laurentius Petri ${ }^{54}$ o Rodericus Petri de Uillaluporum ${ }^{55}$.

\footnotetext{
${ }^{48}$ Sobre este "poderoso magnate leonés", cf. C. ESTEPA DíEZ, Estructura social de la ciudad de León (siglos XI-XIII), León, 1977, pp.289-326, especialmente la p. 317, en la que el citado investigador pone de relieve su relación con la Real Colegiata y cómo en la disputa entre San Isidoro de León y la iglesia de León sobre las tercias y los diezmos, el abad y canónigos de San Isidoro pedían el cuerpo del "canónigo" don Abril para enterrarlo (cf. ACL 8296 (1167, diciembre, 30). Ténganse en cuenta también los diplomas ASIL 145, ASIL 162, ASIL 299 y ASIL 308
}

${ }^{49}$ Seleccionamos los nombres que consideramos suficientemente explícitos, pues otros muchos son demasiado comunes.

${ }^{50}$ En el Obituario 2 (XIII kalendas iulii): Obiit famulus Dei Uelascus Ennici canonicus Sancti Ysidori (Códice IV, fol. 47 r) y en el Obituario 3, el mismo día: Velascus Ennici (signo cruciforme sobre Velascus), Códice III.2, fol. $185 \mathrm{v}$. Pueden relacionarse estos asientos con el documento ASIL 308 (1166, abril, 6. León) que recoge la donación de la Vega de Salamanca a la canónica isidoriana, carta intitulada por el citado Uelascus Ennego, su esposa Amadonna Domingo y su hermana Iusta Ennego. Véase asimismo ASIL 324.

${ }^{51}$ En el Obituario 2 (kalendas nouember) leemos: Obiit famulus Dei Iohannes Romani presbiter canonicus Sancti Ysidori (Códice IV, fol. 54 v). La carta de donación intitulada por este clérigo es el diploma ASIL 309, fechado en mayo de 1170.

${ }^{52} \mathrm{La}$ carta de donación ASIL 310 (fechada el 30 de abril de 1171) es intitulada por este personaje. La noticia de su defunción en el Obituario 2 (IIII nonas octuber) es la siguiente: Obiit famulus Dei Garssia Ramiri (Códice IV, fol. 53 r).

${ }^{53}$ ASIL 314 (1173, agosto, 29) es una carta de donación por la cual Pelagius Iohhannis y su mujer, Maria Pelagii entregan a San Isidoro de León sus posesiones en Robledo de las Traviesas (próximo a Noceda del Bierzo). En el Obituario 2 (IIII idus decembris) se halla la siguiente adición: Obiit famulus Dei Pelagius Iohannis de Nozeda canonicus Sancti Ysidori (Códice IV, fol. $56 \mathrm{v})$.

${ }^{54}$ ASIL 315 (año 1174) recoge una donación de Laurentius Petri y Dominicus Petri. En el Obituario 2: V kalendas marcii: Obiit famulus Dei Laurentius prior de Uilla Alpando presbiter canonicus Sancti Ysidori (signo cruciforme sobre Laurentius) (Códice IV, fol. 40 v) y, el mismo día, en el Obituario 3: Dopnus Laurencius de Uilla Alpando presbiter canonicus (signo cruciforme sobre Laurencius) (Códice III.2, fol. 183 v).

${ }^{55} \mathrm{El}$ diploma que recoge la donación efectuada por Rodericus Petri de Uillalobos es ASIL 364 , fechado en 1211. En el Obituario 2 (II kalendas nouember) se encuentra la siguiente mención: et famulus Dei Rodericus Petri de Uillaluporum, miles, canonicus Sancti Ysidori (signo cruciforme superpuesto) (Códice IV, fol. 54 v). 
La interrelación entre ciertas cartas de donación y los asientos en obituario queda, pues, fuera de toda duda, pero, ¿existe constancia explícita de esta vinculación? Sí, aunque sólo en uno de los diplomas del rico fondo documental isidoriano. En 1222 Villelmus de Pinnu realiza una serie de donaciones a la comunidad isidoriana ${ }^{56}$ :

\begin{abstract}
Dono eciam ad seruicium eiusdem capelle et ad sustentationem duorum canonicorum qui in predicta capella diuinum offitium celebrent im (sic) perpetuum pro anima mea et parentum meorum (...). Insuper dabo uobis hereditatem pro meo anniuersario annuatim faciendo et nomen meum faciatis scribi in uestro libro capituli.
\end{abstract}

La canónica - que admite al benefactor como socio y concanónigocumple su promesa. Por ello, entre los asientos asociados en el Obituario 2 al 24 de septiembre, figura el siguiente:

et famulus Dei Guilelmus del Pin, canonicus Sancti Ysidori, qui reliquid nobis centum morabetinos pro suo anniuersario ${ }^{57}$.

Conocido el itinerario entre la carta de donación y el obituario, situémonos en este libro necrológico para iniciar la segunda etapa de nuestro recorrido.

\title{
2.2. ¿Del pergamino a la piedra? (obituarios y epitafios)
}

Tomando el obituario como punto de partida es posible trazar un camino desde los asientos en este tipo de libro hasta los epitafios isidorianos? A primera vista, la pregunta podría considerarse retórica si tenemos en cuenta las afirmaciones de varios investigadores expertos en epigrafía medieval.

Cuando A. Durán Gudiol acometió el estudio y edición de las inscripciones medievales de la provincia de Huesca, definió las inscripciones necrológicas como "copias en piedra de un Necrologium u Obituarium de un centro eclesiástico" (...) "Desgraciadamente - añadía - no han llegado a nosotros los Necrologia de los importantes centros eclesiásticos altoaragoneses, pero, en cambio, nos ha sido legada parte de los mismos grabada en

\footnotetext{
${ }^{56}$ ASIL 383.

${ }^{57}$ Códice IV, fol. 52 r.
}

«Anuario de Estudios Medievales», 33/1 (2003), pp. 365-415 .- ISSN 0066-5061. 
sillares de los respectivos claustros"58. Asimismo, ocupándose del conjunto epigráfico de la antigua catedral de Roda de Isábena, indicaba que

conserva el mayor número de inscripciones de la provincia de Huesca. Un total de 191. Forman en su conjunto la versión epigráfica del Necrologium catedralicio $^{59}$.

La misma opinión manifiesta el profesor García Lobo en su aproximación al corpus epigráfico de Santo Domingo de Silos:

el resto de las inscripciones, que constituyen la inmensa mayoría de las del claustro, son funerarias -Epitaphia - con dos variedades muy definidas: sepulcrales (...) y necrológicas, en que solamente se recoge la noticia del fallecimiento y cuya fórmula más corriente suele ser obiit. Este último grupo es el más importante numérica y culturalmente. Sus textos están tomados de un Obituario o Necrologio ${ }^{60}$.

Por esta razón, engloba el conjunto epigráfico con la expresión "Obituario en piedra"61. Ni en Roda de Isábena ni en Santo Domingo de Silos se conservan los libros considerados fuente de las inscripciones, su existencia sólo puede conjeturarse y es imposible hoy llevar a cabo un análisis comparativo entre obituarios y epitafios rotenses y silenses ${ }^{62}$.

En San Isidoro de León tenemos la fortuna de acceder a los obituarios en pergamino, pero ¿puede hablarse de un "obituario en piedra" datable entre mediados del siglo XII y primer cuarto del siglo XIII copia -en todo o en parte- de los membranáceos? Si tomamos en consideración las inscripciones supervivientes, la respuesta es no, puesto que el conjunto epigráfico isidoriano objeto de nuestra aproximación carece de epitaphia necrologica propiamente

${ }^{58}$ A. DuRAN Gudiol, O.c., p. 47.

${ }^{59}$ Ibídem, p. 69. Asimismo, señala que "la grabación en piedra del Necrologium rotense no puede ser anterior al año 1225" (Ibidem, p.70)

${ }^{60} \mathrm{~V}$. GARCía LoBo, La epigrafía del claustro de Silos, "El Románico en Silos. IX centenario de la consagración de la iglesia y claustro (1088-1988)", Abadía de Silos, 1990, pp.87-88.

${ }^{61}$ Ibidem, p. 88.

${ }^{62} \mathrm{~A}$ propósito del obituario rotense: "Los canónigos rotenses, que tenían establecido pacto de hermandad con la canónica de Santa María de Pamplona, enviaron a esta catedral una copia de su obituario, que fue incorporado en el de la Seo de Navarra" (A. DURÁN GUDIOL, O.c., p.69). En lo que se refiere al silense, V. García Lobo no duda de su existencia alegando que "el Obituario o Necrologio" es un "códice litúrgico que nunca faltaba en las comunidades monásticas" (V. GARCíA LOBO, La epigrafia del claustro de Silos, p. 88).

«Anuario de Estudios Medievales», 33/1 (2003), pp. 365-415 .- ISSN 0066-5061. 
dichos y sólo corresponde al formulario de éstos uno -correspondiente a la infanta Sancha- grabado en un sepulcro. No se copiaron en piedra las noticias necrológicas de los obituarios, ni en el momento de producirse la muerte ni con cierta o notable posterioridad ${ }^{63}$. Descartada la duplicación, tampoco advertimos un cambio de soporte para los apuntes necrológicos. Es decir, carecemos de ejemplos que muestren cómo, cuando decayó el uso y ampliación de los obituarios en San Isidoro de León - a mediados o en el último tercio del siglo XIII—, se optó por la realización de epitafios necrológicos.

Descartado el traslado textual a la piedra - a modo de epitaphia necrologica - de los apuntes recogidos en los obituarios ipodemos establecer relación entre dichas anotaciones y los epitaphia sepulcralia? Ambas fuentes son netamente distintas. El epígrafe sepulcral informa prioritariamente de un enterramiento y el obituario notifica a la comunidad el nombre de personas y colectivos a los que es preciso recordar en el rezo o en la celebración eucarística, con independendencia de que los beneficiados por la oración estén o no sepultados en el recinto isidoriano. De hecho, algunos de los personajes que intitulan epitafios se hallan ausentes de los libros necrológicos. Fijemos la atención, por ejemplo, en una inscripción sobre mármol localizada en el muro occidental del claustro meridional - pertenece a un sepulcro introducido en la pared- "entre las capillas de San Ignacio y San José"64 y fechada el 1 de julio de 1197:

\section{HIC REQUIESCIT FAMULVS DEI GIRALT DE MONTE MIRATH}

\footnotetext{
${ }^{63}$ Como se advierte en otros centros eclesiásticos. Ya precisaba V. García Lobo que las inscripciones necrológicas son copias de un obituario "sacadas, a veces, muy posteriormente a la fecha del fallecimiento" (cf. V. GARCÍA LOBO, Las inscripciones medievales, p.387; véase análoga observación en ID., La Epigrafía medieval. Cuestiones de método, "Centenario de la Cátedra de Epigrafía y Numismática, Universidad Complutense de Madrid 1900/01-2000/01", Madrid, 2001, p.102). Este fenómeno lo advierte en San Miguel de Escalada (Las inscripciones de San Miguel de Escalada. Estudio crítico, Barcelona, 1982, p.76) y Silos (La epigrafía del claustro de Silos, p.88). "Se trata de inscripciones tardías. Las de Silos obedecen todas ellas a dos manos que actuaron, probablemente, en dos momentos distintos: una hacia finales del siglo XIII y otra en los primeros años del XIV. La pregunta que podríamos formular es ésta: ¿A qué obedece una moda que parece generalizarse en esta época? ¿por qué repetir literalmente lo que ya estaba consignado en el obituario?" (V. GARCÍA LOBO y E. MARTÍN LóPEZ, La escritura publicitaria en la Edad Media. Su funcionalidad, "Estudios Humanísticos. Geografía, Historia, Arte", 18(1996), p. 143).

${ }^{64}$ Cf. J.L. CaStRillón e I. REdOndo, O.c., p.356.
} 


\section{QUI OBIIT IN ERA $\mathrm{M}^{\mathrm{a}} \mathrm{CC}^{\mathrm{a}} \mathrm{XXX}^{\mathrm{a}} \mathrm{V}^{\mathrm{a}} \mathrm{KALENDAS} \mathrm{IULII}{ }^{65}$.}

Pese a insertarse la defunción en el periodo de pleno uso de los obituarios, el citado Giralt está ausente de los mismos y los renglones correspondientes al primer día de julio en los libros necrológicos citados no presentan raspaduras que indiquen la supresión de un asiento ${ }^{66}$.

Constatamos, no obstante, coincidencias entre nombres que intitulan epitafios sepulcrales y adiciones coetáneas en los obituarios de la canónica ${ }^{67}$. La explicación es sencilla: los personajes en cuestión no sólo se encomiendan a las oraciones de los canónigos, sino que, además, se encuentran sepultados en la Real Colegiata. Varios de los documentos del fondo isidoriano, a los que hemos hecho referencia explícita en el apartado anterior, no sólo ponen de manifiesto cómo determinados particulares realizan una donación para garantizar así la celebración de su aniversario - circunstancia que justifica su inclusión en el obituario-, también manifiestan la voluntad de ser enterrados en el recinto de la colegiata, hecho que - de consumarse- explicaría la ejecución paralela de un epitafio sepulcral. Tampoco este hecho indica que un epígrafe funerario se haya realizado copiando el texto del correspondiente asiento necrológico en el libro, pues, además de notables diferencias en el formulario, la información recogida sobre piedra incluye datos distintos a la plasmada en pergamino y no sólo porque el epitafio haga referencia explícita a la sepultura. También pueden ser notables las desemejanzas estilísticas, evidentes éstas cuando comparamos una inscripción rítimica o versificada con la lacónica anotación obituaria.

Detengámonos brevemente en estos aspectos.

Comenzando por el formulario y los datos que componen las noticias, en los tres libros necrológicos analizados es frecuente que las primeras adiciones asociadas a una determinada fecha, y relativas a individuos, se ajusten al siguiente formulario: notificativo obiit seguido de la intitulación del difunto, en nominativo, en la que el nombre sucede al piadoso famulus o famula Dei. A estos elementos mencionados - comunes o fijos- pueden

\footnotetext{
${ }^{65} \mathrm{La}$ primera edición del texto de la inscripción fue realizada por J. LÓPEZ CASTRILLÓN e I. REDONDO, O.c., p.356. Se alude, asimismo, a su texto en M. GómEZ MORENO, O.c., p.214, dando como fecha del fallecimiento la "era 1230 " porque atribuye el numeral $V$-que se acompaña de una $a$ sobrepuesta- a la kalendación

${ }^{66} \mathrm{Hemos}$ revisado también los asientos del $V$ kalendas iulii, pues cabía la posibilidad de un error en el epígrafe, situando una $a$ sobrepuesta en vez de una $o$ sobre el numeral $V$.

${ }^{67}$ Establecemos la contemporaneidad tomando como base las características de la escritura.

«Anuario de Estudios Medievales*, 33/1 (2003), pp. 365-415 .- ISSN 0066-5061.
} 
incorporarse otros: especificación de la vinculación del difunto a la comunidad isidoriana:

Obiit famulus Dei Petrus Gallegus, conuersus huius ecclesie ${ }^{68}$,

responsabilidad en la canónica:

et famulus Dei Pelagius Iohannis, camerarius, presbiter canonicus Sancti Ysidori ${ }^{69}$.

u otra condición social:

Obiit famulus Dei Petrus Fernandi, miles ${ }^{70}$,

El año del fallecimiento figura en raras ocasiones si el difunto no pertenece a la familia real o desempeñó alta responsabilidad en San Isidoro. Recojamos, pues, una de las excepciones:

Obiit famulus Dei domnus Petrus de Deo, presbiter canonicus Sancti Ysidori. Era $\mathrm{M}^{\mathrm{a}} \mathrm{CC}^{\mathrm{a}} \mathrm{L}^{\mathrm{a}} \mathrm{VI}^{\mathrm{a}}{ }^{71}$,

La expresión del año es más frecuente en el tenor de un epitafio sepulcral. Por ello, ciertas inscripciones incluyen precisiones cronológicas ausentes del correspondiente asiento en el libro necrológico. Tomemos dos ejemplos significativos, eligiendo noticias recogidas en los obituarios 1 y 2 respectivamente.

En el que hemos llamado Obituario 1, como segunda memoria asociada al 27 de septiembre, figura el escueto apunte

Micahel Dominici ${ }^{72}$

${ }^{68}$ Obituario 2, Códice IV, fol. $38 \mathrm{r}$.

${ }^{69}$ Obituario 2, Códice IV, fol. $43 \mathrm{v}$.

${ }^{70}$ Obituario 1 , Códice IV, fol. $1 \mathrm{v}$.

${ }^{71}$ Obituario 2, Códice IV, fol. 44 r.

${ }^{72}$ Códice IV, fol. 5 v.

«Anuario de Estudios Medievales», 33/1 (2003), pp. 365-415 .- ISSN 0066-5061. 
precedido de la conjunción copulativa et para añadirlo al asiento anterior, adición que contaba con el explícito notificativo Obiit y, por lo tanto, ya de repetición innecesaria. Conocido el día y el mes, nada sabemos del año en el que aconteció la muerte. Sin embargo, un paseo por el claustro meridional isidoriano permite descubrir en el muro este, dispuesto en dos sillares consecutivos próximos a la puerta de la sala capitular, el siguiente letrero:

\section{†HIC REQVIESCIT FAMVLVS DEI MICAHEL DOMINICI QVI OBIIT} ERA M ${ }^{\mathrm{a}}$ CC $^{\mathrm{a}}$ ET QVOTVM $\mathrm{V}^{\mathrm{o}} \mathrm{K} A \mathrm{~L} E N D A S$ OCTOBRIS ${ }^{73}$.

Encabeza las adiciones vinculadas al 31 de octubre en el Obituario 2:

Obiit famulus Dei Matheus presbiter ${ }^{74}$.

Si fijamos la vista en un zócalo del muro oriental del claustro, entre la sala capitular o capilla "de los Quiñones" y la capilla "de los Castañones", descubrimos el año en el que falleció dicho clérigo:

\section{[HI]C R]EQVIESCIT FAMVLVS DEI MATHEVS PRESBITER SVB ERA $\mathrm{M}^{\mathrm{a}} \mathrm{CC}^{\mathrm{a}} \mathrm{XXX}{ }^{\mathrm{a}}$ ET QVOTVM II KALENDAS NOVEMBRIS.}

Evidentemente, el responsable de las dos inscripciones transcritas no se basó en las correspondientes adiciones de obituario, menos completas, como tampoco lo hizo el artífice de otro epitafio localizado en la misma galería del claustro. El letrero, mutilado, se halla en un sillar desplazado de su ubicación originaria y ahora depositado en el suelo - sobre otro anepigráfico- próximo a la puerta de acceso a la capilla "de los Omañas". Reza así:

†HIC REQVES[CIT] FAMVLA DEI IVSTA SALVATORIS. IN ERA $\mathrm{M}^{\mathrm{a}} \mathrm{C}^{\mathrm{a}} \mathrm{LXXXX}{ }^{\mathrm{a}} \mathrm{ET}$ QVOTVM XIII K[ALENDAS] M[A]II. HIC IN [....].

Es una noticia en el Obituario 1 -asociada, como cabría esperar, al 19 de abril (XIII kalendas madii) - la que podemos relacionar con el epígrafe, pero difiere la información recogida en la nota: se especifica la relación de

\footnotetext{
${ }^{73}$ Puede verse la reproducción fotográfica de esta inscripción en V. GARCíA LOBO y E. MARTÍN LÓPEZ, De epigrafía medieval. Introducción y álbum, León, 1995, pp. 34 y 107 (lámina XXIII.2).

${ }^{74}$ Códice IV, fol. 54 v.

«Anuario de Estudios Medievales», 33/1 (2003), pp. 365-415 .- ISSN 0066-5061.
} 
parentesco de la fallecida con un miembro de la comunidad isidoriana y se omite el año del óbito:

Obiit famula Dei Iusta Saluatoris, mater Dominicus Dominici canonicus Sancti Ysidori $^{75}$.

Si nos ocupamos del estilo, no es difícil tampoco encontrar ejemplos significativos. Elegimos como protagonista al primer prelado de la canónica reglar: el prior Pedro Arias, cuya defunción tuvo lugar el 5 de mayo de 1150. $\mathrm{Su}$ sepulcro se localiza ahora en la estancia abierta en la galería occidental del claustro más próxima al muro norte, contigua a la capilla de San Ignacio ${ }^{76}$.

La inscripción que nos interesa se distribuye en tres renglones que coinciden con los espacios resaltados de la tapa acanalada ${ }^{77}$. El epígrafe se ha redactado en versos leoninos,

LAVDE PRI[O]R DIGNVS PETRVS PIVS ATQUE BENIGNVS,

QVI MISIT MORES ET NORMA CANONICORVM PRIMVS IN HAC PATRIA DOMINO TRIBVENTE POLORVM REGNANS CVM CHRISTO TVMVLO REQUIESCIT IN ISTO ${ }^{78}$.

${ }^{75}$ Códice IV, fol. $3 \mathrm{r}$.

${ }^{76}$ Sobre la localización anterior de este sepulcro y del correspondiente al abad Menendo, al que haremos alusión más adelante, véase J.L. CASTRILLÓN e I. REDONDO, O.c., pp.351-358. Con respecto al traslado del sepulcro "se eligió como paraje más oportuno al objeto la capilla de Nuestra Señora de la Asunción, en la que, después de habilitada convenientemente, hubieron de ser colocados con carácter provisional los cinco sarcófagos mencionados, trocando, con esta inesperada instalación, la abandonada estancia su antiguo destino en panteón abacial" (Ibídem, p. 357). Estaban estas y otras sepulturas ocultas en 1885, cuando se redacta el informe por los dos autores citados. "Lo primero que fijó su atención fue el cerramiento de la parte inferior de dos arcos, a cada lado del central, de los cinco que forman la crujía contigua al templo, que es la del lado sur, única que se conserva de obra antigua aunque no primitiva. (...) Demolióse la parte superior del cerramiento del arco más oriental, y dejóse ver un sarcófago de piedra común con la tapa acanalada en cuyas partes salientes se halla el epitafio, a excepción de la fecha, abierta en uno de los lados mayores de la urna: es el del venerable Pedro Arias (Ibídem, p.352). Sin embargo, tres siglos antes, el epitafio no estaba oculto. Entre los textos que recoge el Códice XCI de la biblioteca capitular, anteriormente citado, se halla una Historia de la Colegiata redactada por el prior Juan Durón. En este relato se inserta la siguiente noticia relativa al prior Pedro Arias: "Murió en la era de 1188, según consta del letrero de su sepultura que está frontero de la puerta de San Agustín en un arco..." (fol. 116 r). "En 1960 se colocaron estos sarcófagos en la última sala del claustro, pegada a la muralla" (A. VIÑAYO GONZÁLEZ, Abadía de San Isidoro, p. 759).

${ }^{77}$ Puede verse la reproducción fotográfica de este sepulcro en V. GARCÍA LOBO y E. MARTíN LÓPEZ, De epigrafía medieval, p. 105 (lámina XXII).

${ }^{78}$ Una deficiente lectura ha dado lugar a una interpretación errónea del segundo de los renglones grabados y, así, la $Q$ capital inicial con pequeña $i$ inserta, que debe interpretarse como abreviatura de Qui o Qvi (Qui misit), fue confundida con una $O$, construyéndose así la peculiar forma verbal omisit que da lugar a la extraña $-\mathrm{y}$ difícilmente traducible - afirmación "omisit mores et normam...". Este error - sobre el que ya llamamos la atención en A. SUÁREZ, Cargos

«Anuario de Estudios Medievales», 33/1 (2003), pp. 365-415 .- ISSN 0066-5061. 
Nada tiene que ver estilísticamente esta elaborada leyenda con el asiento en el obituario, mucho más simple, aunque también en él se hace referencia al importante papel desempeñado por Pedro Arias en la implantación de una comunidad de canónigos regulares en San Isidoro de León. Esta noticia -dispuesta en el Obituario 2- encabeza las memorias asociadas a las III nonas maii y reza así:

Obiit famulus Dei Petrus Ariae, prior primus in hac aecclesia canonici ordinis edificator. In era $\mathrm{M}^{\mathrm{a}} \mathrm{C}^{\mathrm{o}} \mathrm{LXXX}{ }^{\mathrm{a}} \mathrm{VIII}^{\mathrm{a}}{ }^{79}$.

Demostrado, pues, que los epitafios sepulcrales y los obituarios isidorianos son objetos independientes, no debemos descartar, sin embargo, que noticias reproducidas en estos libros necrológicos se hayan tenido en cuenta para completar o ampliar - con cierta posterioridad - algunos epitaphia sepulcralia. Sin que podamos afirmarlo con rotundidad -repetimos que el estudio sistemático del corpus epigráfico isidoriano es aún una tarea en curso- tal parece ser el caso del epitafio que se dispone en la sepultura de Menendo, primer prelado de la canónica con dignidad abacial. El sepulcro se halla actualmente en la misma estancia que el de Pedro $\operatorname{Arias}^{80}$ y la inscripción presenta varios problemas: signos de lectura dudosa, mutilación, trazos aparentemente superfluos bajo el segundo renglón de texto (quizá restos de un epígrafe anterior), etc. Además, ésta parece haberse realizado al menos en dos fases diferenciables por los caracteres gráficos, el tratamiento de la piedra en la que se abre la escritura y el estilo. La primera parte del epígrafe, versificada, dice así:

en la comunidad de San Isidoro de León. Fuentes para su estudio entre 1148 y 1248, "Monjes y monasterios españoles", II, San Lorenzo del Escorial, 1995, p. 1049 y nota 77- arranca del informe elaborado en 12 de junio de 1885 por J. LÓPEZ CASTRILLÓN e I. REDONDO, O.c., p. 353. En la introducción a este artículo, F. Fita mostró su extrañeza con las siguientes palabras: "El segundo verso Omisit mores et normam canonicorum paréceme oscuro e inadecuado a la verdad histórica. Lejos de omitir, cometió y confió Pedro Arias a sus secuaces la norma Agustiniana de la regla canonical bajo la inspiración del Señor de los cielos" (Ibídem, p. 351). Sin embargo, sorprendentemente, años después recoge J. Pérez Llamazares la leyenda sepulcral del sarcófago de Pedro Arias con el mismo error que introdujeron los miembros de la Comisión de monumentos (Historia de la Real Colegiata de San Isidoro de León, León, 1927, p. 140).

${ }^{79}$ Obituario 2, Códice IV, fol. 44 v.

${ }^{80} \mathrm{La}$ reproducción fotográfica del sepulcro, con la imagen del abad grabada en la tapa, y su inscripción en A. VIÑAYO GONZÁLEZ, Real Colegiata de San Isidoro: Historia, Arte y Vida, León, 1998, p. 26.

«Anuario de Estudios Medievales», 33/1 (2003), pp. 365-415 .- ISSN 0066-5061. 


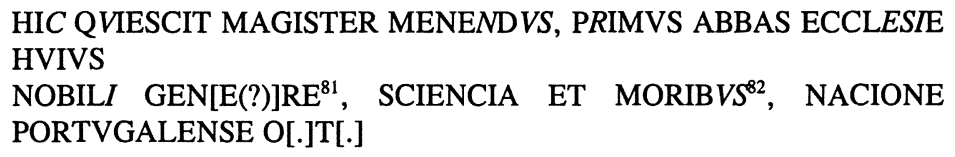

La última palabra, de la que se conservan sólo los caracteres extremos y un trazo del signo intermedio, puede considerarse vocablo intersección entre las dos partes. Aparentemente, la $T$ final y quizá la letra media podrían corresponder ya a la que consideraremos segunda fase del epígrafe, puesto que parece haberse intervenido sobre lo escrito, alterando el término. Esta palabra se ha resuelto con el notificativo $O[B I I] T$, tomando como referencia la fecha que se explicita a continuación ${ }^{83}$. Sin embargo, no podemos descartar que la $O$ inicial abriese originariamente otra palabra - ¿ortus $?^{84}$ - y que una modificación posterior la transformase en el pretendido Obiit para enlazar con la segunda parte.

Esta supuesta ampliatio consiste en la especificación de la fecha del fallecimiento: el 23 de mayo de 1167:

$\mathrm{E} R A \mathrm{M}^{\circ} \mathrm{CC}^{\circ} \mathrm{V}^{\circ}, \mathrm{X}^{\circ}[\mathrm{K}] A \mathrm{~L} E N D A \mathrm{~S}$ IVNII.

En el Obituario 2, asociada al $X$ kalendas iunii figura la siguiente noticia relativa a la defunción del abad:

Obiit famulus Dei abbas domnus Menendus Sancti Ysidori. Era $\mathrm{M}^{\mathrm{a}} \mathrm{CC}^{\mathrm{a}} \mathrm{V}^{\mathrm{a} 85}$.

\footnotetext{
${ }^{81}$ Incorporamos la vocal $E$ teniendo en cuenta la palabra de la que forma parte, pero el carácter es confuso, pues parecen advertirse los dos trazos de una $A$ sin travesaño.

${ }^{82}$ ¿Formó parte la expresión "nobili genere, sciencia et moribus" de algún otro letrero funerario isidoriano? En la relación de personas sepultadas en la Colegiata que ofrece el Códice $\mathrm{XCI}$, leemos lo siguiente: ¿El conde don Sancho: dice la letra que fue noble en ciencia y costumbres? (fol. $88 \mathrm{r}$ ).

${ }^{83}$ Forma verbal que aparece en las ediciones de J.L. CASTRILlÓN e I. REDONDO, O.c., p. 354 y J. PÉREZ LlAMAZARES, Historia, p. 142. Advertimos que también en otros aspectos difiere nuestra lectura de las realizadas por los anteriormente citados.

${ }^{84}$ Un exhaustivo estudio del texto del epígrafe se debe a L. MARTínEZ ÁNGEL, Sobre el cursus rhythmicus en los epitafios de los abades Menendo de San Isidoro y Diego I de Sahagún y el conocimiento de Salustio en el León del siglo XII, "Estudios Humanísticos. Filología", 23 (2001), pp. 329-334. Agradecemos al Dr. L. Martínez Ángel sus valiosas orientaciones.

${ }^{85}$ Códice IV, fol. 45 v. 
El asiento es también, curiosamente, obra de dos manos. A un segundo artífice corresponde la incorporación del año de fallecimiento. Apuntamos, con las debidas reservas, que el epitaphium sepulcrale de Menendo pudo ser ampliado tomando como referencia la anotación obituaria.

\section{3. ¿De la piedra al pergamino? (epitafios y obituarios)}

Cuando describíamos someramente los tres obituarios isidorianos de origen medieval indicábamos que los dos primeros -1 y 2 - podían ser considerados originales o vivos, al menos en lo referente a las noticias correspondientes al periodo objeto de nuestra aproximación, hecho delatado, entre otros aspectos, por su extraordinaria heterogeneidad gráfica. Caso bien distinto constituía, advertíamos, el Obituario 3, de una sola mano originaria que copió en el primer quinto del siglo XIII la totalidad de las noticias que hasta el momento contenía el Obituario 2. La novedad respecto al libro necrológico empleado como principal modelo es la incorporación en el tercero de las memorias de reyes, reinas y otros miembros de la casa real cuyo óbito había tenido lugar en ocasiones con notable anterioridad al momento en el que los canónigos regulares se establecieron en el centro isidoriano. ¿De dónde obtuvo el artífice del Obituario 3 la necesaria información sobre la fecha de defunción de estos personajes especialmente relevantes para la Real Colegiata?

La inclusión de las noticias necrológicas correspondientes a los monarcas y otros personajes de la familia real fallecidos en el periodo de utilización de los obituarios 1 y 2 , no tiene nada de excepcional. Tales personajes se hallan muy cercanos a la comunidad y su condición de benefactores se pone de relieve en buen número de diplomas isidorianos ${ }^{86} . \mathrm{La}$ presencia de Alfonso VII, su hermana Sancha o Fernando II en el Obituario 2 está, pues, plenamente justificada, aun cuando los dos reyes citados no

${ }^{86}$ Sirvan de ejemplo los siguientes: ASIL 146, ASIL 151, ASIL 153, ASIL 156, ASIL 161, ASIL 162, ASIL 164, ASIL 167, ASIL 168, ASIL 169, ASIL 170, ASIL 172, ASIL 173, ASIL 176, ASIL 178, ASIL 181, ASIL 182, ASIL 183, ASIL 185, ASIL 186, ASIL 187, ASIL 188, ASIL 192, ASIL 193 y ASIL 746.

«Anuario de Estudios Medievales», 33/1 (2003), pp. 365-415 .- ISSN 0066-5061. 
recibieron sepultura en el recinto isidoriano ${ }^{87}$. Es el caso de Alfonso VII, cuya memoria se incorpora al 21 de agosto (XII kalendas september (sic)):

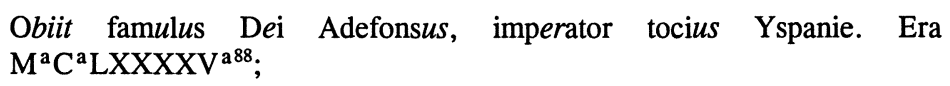

y de Fernando II, fallecido en 1188 (su óbito se asocia al XII kalendas februarii):

Obiit famulus Dei Fredenandus rex, Adefonsi imperatoris filius. Sub era $\mathrm{M}^{\mathrm{a}} \mathrm{CC}^{\mathrm{a}} \mathrm{XXVI}{ }^{\mathrm{a}}{ }^{89}$.

Las dos notas transcritas presentan formulario análogo al del resto de los asientos que se van insertando en el libro a medida que se produce el correspondiente fallecimiento. Sólo aparece en el Obituario 2 la mención a un monarca muy anterior al establecimiento de los canónigos en San Isidoro, se trata de Fernando I. Figura su memoria en este obituario asociada al $X$ kalendas ianuarii y la redacción de la adición es más compleja que las anteriormente editadas:

et Fredenandus rex totius Yspanie qui transtulit corpus beati Isydori ab Yspali in Legione. Era $\mathrm{M}^{\mathrm{a}} \mathrm{C}^{\mathrm{a}} \mathrm{III}^{\mathrm{a} 90}$.

Constituye este apunte una de las excepciones más relevantes del Obituario 2, puesto que, repetimos, en la mayor parte de los casos, la incorporación de la adición relativa a un fallecimiento tiene lugar inmediatamente después de conocerse el hecho, según revelan las características de la escritura. Sin embargo, un aspecto resulta especialmente relevante: la mano

\footnotetext{
${ }^{87}$ Aunque el momento de su fallecimiento ya no pertenece al periodo cronológico elegido para nuestra aproximación, no podemos omitir, por su importancia, cómo también figura en el Obituario 2 la noticia necrológica referida a Álfonso IX. Benefactor de la canónica y monarca que tampoco fue inhumado en recinto isidoriano, la comunidad isidoriana lo recuerda el $X$ kalendas octobris: Obiit famulus Dei Adefonsus rex Legionis et Gallecie. Era $\mathrm{M}^{\mathrm{a}} \mathrm{CC}^{\mathrm{a}} \mathrm{LX}^{\mathrm{a}}$ VIII ${ }^{\mathrm{a}}$ (Códice IV, fol. 52 r).

${ }^{88}$ Códice IV, fol. $50 \mathrm{v}$.

${ }^{89}$ Códice IV, fol. 39 r. Como cabría esperar, aparece también copiada en el Obituario 3: Obiit famulus Dei Fredenandus rex, Adefonsi imperatoris filius, era $\mathrm{M}^{\mathrm{a}} \mathrm{CC}^{\mathrm{a}} \mathrm{XXVI}^{\mathrm{a}}$ (Códice III.2, fol. 182 v). La mutilación de Obituario 3 impide que podamos reproducir la adición referida a Alfonso VII, pues ha desaparecido el folio correspondiente a este día del calendario.

${ }^{90}$ Códice IV, fol. $57 \mathrm{r}$.

«Anuario de Estudios Medievales», 33/1 (2003), pp. 365-415 .- ISSN 0066-5061.
} 
que introdujo esta noticia antigua es la misma a la que se debe el Obituario 3 , datable en el primer quinto del siglo XIII' ${ }^{91}$.

Fernando I recibió sepultura en la Real Colegiata, al igual que, casi un siglo más tarde, su bisnieta Sancha. La defunción de la infanta, acaecida en 1159, es una de las noticias más divulgadas en San Isidoro de León, sin duda por tratarse de una gran benefactora a la que los canónigos se hallaban especialmente agradecidos. A diferencia de lo que sucede en la mayor parte de los casos, se conservan, creemos, todos los testimonios escritos que tuvieron como fin comunicar y recordar su muerte, por lo que es posible realizar un estudio comparativo de la información transmitida en unos y otros objetos y seguir el recorrido del mensaje funerario.

El fallecimiento de la infanta se inscribe en el periodo de máxima utilización del Obituario 2. Es lógico, por tanto, que los canónigos incluyesen el nombre entre los encomendados a sus plegarias. Probablemente, la adición obituaria es la primera puesta por escrito de la luctuosa noticia. Se trata de un apunte escueto que encabeza los correspondientes al último día de febrero (II kalendas marcii):

Obiit famula Dei infans domna Sancia, soror imperatoris Adefonsi. Era $M^{\mathrm{a}} \mathrm{C}^{\mathrm{a}} \mathrm{LXXXX}^{\mathrm{a}} \mathrm{VII}^{92}$.

Una mano distinta, pero poco posterior a la anterior -teniendo en cuenta las características de la escritura - introduce la noticia en un texto litúrgico stricto sensu: el anteriormente citado Martirologio. Indica esta mención especial aprecio hacia la infanta. La nota -inserta también el 28 de febrero- es casi idéntica a la recogida en el Obituario 2:

${ }^{91} \mathrm{La}$ leyenda no se encuentra ahora en el Obituario 3, debido a la mutilación del libro. A pesar de haber fallecido casi un siglo antes de la llegada de los canónigos regulares a San Isidoro, el recuerdo de este monarca, a quien se debe el traslado de los restos del santo titular, estaba muy presente en la vida litúrgica de la comunidad. Por ello, es uno de los pocos nombres añadidos al martirologio que forma parte, al igual que los obituarios 1 y 2 , del Códice IV: Obiit famulus Dei rex domnus Fredenandus tocius Yspanie. Era $\mathrm{M}^{\mathrm{a}} \mathrm{C}^{\mathrm{a}}$ III ${ }^{\mathrm{a}}$ (Códice IV, fol. $36 \mathrm{r}$ ). En el Obituario 2 la mención se ubica el 23 de diciembre y en el martirologio se adscribe al día 27 (VI kalendas ianuarii), día que coincide con el aportado por otras fuentes como la crónica silense (cf. A. VIÑAYO GONZALLEZ, Fernando I (1035-1065), Burgos, 1999, p. 219). También aparece fechado su fallecimiento la III feria, VI kalendas ianuarii, era $T^{a}$ CII $^{p}$ en la lápida con escritura visigótica que se sitúa sobre la puerta tabicada de acceso a la iglesia desde el panteón (véase la reproducción fotográfica de este monumentum aedificationis en A. VIÑAYO GONZÁLEZ, Real Colegiata, p.13). Las copias literarias de su epitafio, ahora desaparecido, presentan lecturas distintas, por lo que ignoramos si en la inscripción funeraria figuraba VI kalendas ianuarii (M. RISCO, O.c., pp. 149150) o $X^{o}$ kalendas ianuarii (ASIL, Códice XCI, fol. 85 r).

${ }^{92}$ Códice IV, fol. $41 \mathrm{r}$.

«Anuario de Estudios Medievales», 33/1 (2003), pp. 365-415 .- ISSN 0066-5061. 
Obiit famula Dei infans domna Sancia, soror Adefonsi imperatoris. Era $\mathrm{M}^{\mathrm{a}} \mathrm{C}^{\mathrm{a}} \mathrm{LXXXX}{ }^{\mathrm{a}} \mathrm{VII}^{\mathrm{a} 93}$.

El tercer paso en la transmisión de la noticia podría constituirlo el escueto epígrafe mutilado que se localiza en la cabecera de su sarcófago ${ }^{94}$ :

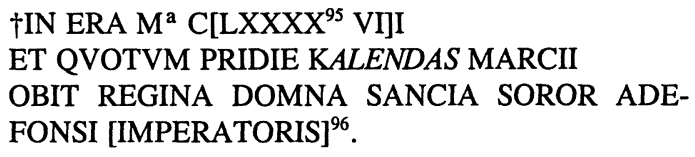

La comparación entre este texto - en piedra- y los anteriores -en pergamino- pone de manifiesto coincidencias tanto en formulario como en los datos contenidos ${ }^{97}$. Sin embargo, debemos destacar una diferencia significativa: en el epitafio Sancha es denominada reina y no infanta ${ }^{98}$.

Una cuarta plasmación de la noticia la constituye la inscripción grabada sobre la cubierta del sarcófago, dispuesta en tres renglones paralelos al eje longitudinal del sepulcro ${ }^{99}$. Este epitafio, elogioso en extremo, se distancia notablemente de los apuntes anteriores por su estilo versificado y laberíntica redacción:

${ }^{93}$ Códice IV, fol. 13 v.

${ }^{94} \mathrm{La}$ reproducción fotográfica del sepulcro y sus letreros en V. GARCÍA LOBO y E. MARTíN LóPEZ, De epigrafia medieval, lámina XXVII, p. 115. El profesor V. García Lobo ha dedicado especial atención a estas inscripciones. A propósito del epitafio que acabamos de transcribir advierte cómo "pudo haber sido trazado inmediatamente después del enterramiento de la infanta" (V. GARCía LOBO, La epigrafía medieval, p. 93).

${ }^{95}$ Deteriorado el epígrafe y, teniendo en cuenta el espacio disponible, cabe también la posibilidad de que tras el numeral $L$ se dispusiese, como equivalente de cuarenta, una X aspada.

${ }^{96} \mathrm{La}$ referencia al emperador figuraría en el cuarto renglón desaparecido y en el que sólo vemos un carácter confuso, tal vez una $N$, en cuyo caso habríamos de transcribir inperatoris.

${ }^{97}$ Como hemos señalado anteriormente, si el epígrafe no se hubiese dispuesto en el sepulcro, lo consideraríamos un epitafio necrológico propiamente dicho.

${ }^{98} \mathrm{En}$ los documentos custodiados en San Isidoro se alternan ambos títulos en las intitulaciones y/o suscripciones: regina (ASIL98, ASIL 150, ASIL 151, ASIL 153, ASIL 154-160, ASIL 298, ASIL 299) e infanta o infantissa (ASIL 137, ASIL 138, ASIL 142, ASIL 144-146, ASIL 155-157, ASIL161). Como señala Lucas de Tuy en el Chronicon Mundi, Alfonso VII "Habebat sororem nobilissimam (...) nomine Sanciam quam, ea hora qua a Legionensibus et Castellanis est confirmatus in regem, secum sedere fecit et reginam uocari iussit" (ASIL, Códice XX, fol. 115r).

${ }^{99}$ Sobre la sucesión temporal de los epitafios, cf. V. GARCÍA LOBO, Las inscripciones, p.388. Este investigador no duda en fijar la ejecución de este epígrafe también en 1159 (La escritura publicitaria en la Península Ibérica. Siglos X-XIII: Inschrift und Material. Inschrift und Buchschrift, München, 1999, p.167).

«Anuario de Estudios Medievales», 33/1 (2003), pp. 365-415 .- ISSN 0066-5061. 
¿DEL PERGAMINO A LA PIEDRA? ¿DE LA PIEDRA AL PERGAMINO?

†ESPERIE SPECVLVM, DECVS ORBIS, GLORIA REGNI, IUSTICIE

CVLMEN ET PIETATIS APEX.

†SANCIA PRO MERITIS INMENSVM NOTA PER ORBEM. PRO

DOLOR! EXIGVO CLAVDERIS IN TVMVLO.

$\dagger$ SOL BIS SEXCENTOS DEMTIS TRI[B]VS EGERAT ANNOS CVM PIA

SVBCVBVIT. FINIS ERAT FEBRVARII.

No resulta fácil a un profano interpretar la inscripción y determinar con rapidez a qué personaje correspondían comentarios tan laudatorios, pese a la inclusión del nombre Sancia, sin tener en cuenta el epígrafe situado en la cabecera. Tal vez por ello se procedió a introducir en la misma tapa un letrero más, en prosa, intercalado en el anterior: los renglones que lo componen se disponen aprovechando los espacios interlineares del versificado. $\mathrm{Si}$ atendemos a su texto, es fácil relacionarlo con las noticias en el obituario y el martirologio, así como con el primer epígrafe del sarcófago. Se ajusta al formulario de un epitafio sepulcral usual, puesto que comienza con el notificativo hic requiescit, y recoge los datos esenciales: nombre y condición de la difunta - se menciona otra vez como reina- y fecha de la muerte. A estos datos imprescindibles se incorporan ahora los relativos a su filiación y el importante papel desempeñado por Sancha cuando se decidió el establecimiento de los canónigos regulares del monasterio de Carbajal en San Isidoro $^{100}$

†HIC REQVIESCIT REGINA DOMNA SANCIA, SOROR INPERATORIS ADEFONSI, FILIA URRACHE REGINE ET RAIMVNDI.

HAEC STATVIT ORDINEM REGVLAR[IVM] CANONICORVM IN ECCLESIA ISTA; ET QVIA DICEBAT BEATVM YSIDORVM

SPONSVM SVVM, VIRGO OBIIT ERA $\mathrm{M}^{\mathrm{a}} \mathrm{C}^{\mathrm{a}} \mathrm{LXL}^{\mathrm{a}}$ VII ${ }^{\mathrm{a}}$ PRIDIE KALENDAS MARCII.

Si comparamos los caracteres gráficos del epitafio con los letreros destacados en códices originarios del scriptorium isidoriano en el cruce entre los siglos XII y XIII y en el primer cuarto de la decimotercera centuria ${ }^{101}$,

\footnotetext{
${ }^{100} \mathrm{Cf}$. ASIL 146.

${ }^{101}$ No olvidemos que, como señala V. García Lobo, "En muchas ocasiones, como nos va a enseñar el fenómeno gráfico de San Isidoro, ordinatores y calígrafos serán las mismas personas, que trabajan indistintamente sobre la piedra y sobre el pergamino" (Las inscripciones, p. 376).

«Anuario de Estudios Medievales», 33/1 (2003), pp. 365-415 .- ISSN 0066-5061
} 
hallamos notables semejanzas ${ }^{102}$. La letra puede ser coetánea, pues, al Obituario 3 y, por ello, a la siguiente noticia en él recogida:

Obiit famula Dei regina domna Sancia, soror imperatoris Adefonsi, huius ordinis fundatrix in Christo, que requiescit in ecclesia ista. Era $\mathrm{M}^{\mathrm{a}} \mathrm{C}^{\mathrm{a}} \mathrm{XC}^{\mathrm{a}} \mathrm{VII}^{\mathrm{a}}{ }^{103}$.

Son varios los aspectos que cabe poner de relieve. En primer lugar, y pese a que, como hemos señalado repetidamente, el Obituario 3 copia el Obituario 2, este asiento no ha tomado como base el correspondiente en el libro necrológico anterior: Sancha aparece en la intitulación como reina, no como infanta y, además, se incorporan datos no transmitidos en la anotación obituaria más antigua. En segundo lugar, la especificación regina relaciona la leyenda del Obituario 3 con las que recogen los dos letreros en prosa dispuestos sobre el sarcófago de la infanta. En tercer lugar, el amanuense al que se debe el Obituario 3 indica que Sancha está inhumada en el recinto isidoriano. ¿Para redactar la noticia necrológica, se basó el copista en un epitafio? La respuesta afirmativa supondría abrir un nuevo camino: la transmisión de la información de la piedra al pergamino. Pero ¿es indiscutible esta afirmación?

La noticia necrológica alusiva a la infanta en el Obituario 3 podemos considerarla un puente. Nos permite enlazar con otras anotaciones en los escasos folios supervivientes del citado Obituario: un conjunto de apuntes relativos a monarcas y otros miembros de la familia real, asientos peculiares por varias razones:

a) Los fallecimientos consignados pudieron acaecer en fechas previas al establecimiento de la canónica regular en San Isidoro de León a mediados del siglo XII. Es el caso, por ejemplo, de Vermudo II (se incorpora el apunte necrológico el III nonas ianuarii)

Obiit famulus Dei Rex domnus Veremudus Ordonii qui requiescit in ecclesia

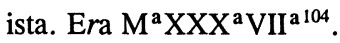

\footnotetext{
${ }^{102}$ Los códices VI, X.1, X.2 así como el Obituario 3 (en el Códice III.2) repetidamente citado, que cuenta con caracteres destacados análogos en el encabezamiento de cada mes. Sobre las características de la escritura notoria en estos libros, cf. A. SUÁREZ GONZÁLEZ, Patrimonio cultural II, p. 243 e ID., Patrimonio cultural III, pp. 96-97 y 509-604.

${ }^{103}$ II kalendas marcii (Códice III.2, fol. 184 r).

${ }^{104}$ Códice III.2, fol. 182 r.

«Anuario de Estudios Medievales», 33/1 (2003), pp. 365-415 .- ISSN 0066-5061.
} 
su esposa, Elvira (el V kalendas februarii):

Obiit famula Dei Regina domna Geloira, vxor regis Veremudi Ordonii ${ }^{105}$.

y Vermudo III, fallecido en 1037. La comunidad de canónigos adscribe el óbito de este monarca al VIII kalendas marcii ${ }^{106}$ :

Obiit famulus Dei ${ }^{107}$ rex domnus Veremudus iunior, filius regis Adefonsi, qui requiescit in ecclesia ista. Era $\mathrm{M}^{\mathrm{a}} \mathrm{LXX}^{\mathrm{a}} \mathrm{V}^{\mathrm{a} 108}$.

b) La fuente de la que se toman estas noticias del tercer libro necrológico no es, y en esto suponen una excepción, el Obituario 2. Excluido este segundo obituario, cabría situar el origen de la información en el martirologio litúrgico o en el primer obituario, pero ambos textos pueden descartarse también, según se deduce de los siguientes ejemplos.

La defunción de la segunda esposa de Fernando II, Teresa, tuvo lugar en $1180 \mathrm{y}$, por lo tanto, se inserta en el periodo de uso de los dos primeros obituarios isidorianos conservados. No figura la noticia en el segundo libro necrológico, pero sí en el Obituario 1, adscrita al 7 de febrero (VII idus februarii). La leyenda reza así:

Obiit famula Dei regina domna Tharasia. Era $\mathrm{M}^{\mathrm{a}} \mathrm{CC}^{\mathrm{a}} \mathrm{XVIII}{ }^{\mathrm{a}}$

En el Obituario 3, sin embargo, la información es más amplia:

Obiit famula Dei regina domna Tarasia, vxor regis Fernandi, que requiescit in ecclesia ista. Era $\mathrm{M}^{\mathrm{a}} \mathrm{CC}^{\mathrm{a}} \mathrm{XVIII}{ }^{\mathrm{a} 109}$.

También podemos destacar la mención a la reina Urraca, fallecida en 1126. Junto a su hija Sancha y a Fernando I, tuvo el honor de figurar en el martirologio de los reglares, en concreto, entre las referencias a los santos

\footnotetext{
${ }^{105}$ Códice III.2, fol. 182 v.

${ }^{106} \mathrm{No}$ coincide ni el día ni el mes con el recogido en otras fuentes (primeros días de septiembre), cf. A. VIÑAYO GONZÁLEZ, Fernando I (1035-1065), Burgos, 1999, p. 25.

${ }^{107} \mathrm{~A}$ continuación una $V$ superflua. Quizá la inicial de Veremudus que se situó en lugar equivocado y no fue raspada.

${ }^{108}$ Códice III.2, fol. 183 v.

${ }^{109}$ Códice III.2, fol. $183 \mathrm{r}$.

«Anuario de Estudios Medievales», 33/1 (2003), pp. 365-415 .- ISSN 0066-5061.
} 
conmemorados el 7 de marzo (nonas marcii) y los recordados el 8 de marzo (VIII idus marcii):

Obiit famula Dei regina dompna Vrraca. Era $M^{\mathrm{a}} \mathrm{C}^{\mathrm{a}} \mathrm{LXIIII}{ }^{\mathrm{a} 110}$.

La noticia en el Obituario 3 no sólo es más completa sino que, además, encabeza las memorias asociadas al 10 de marzo (VI idus marcii):

Obiit famula Dei regina domna Vrracha, mater inperatoris Adefonsi, que requiescit in ecclesia ista. Era $\mathrm{M}^{\mathrm{a}} \mathrm{C}^{\mathrm{a}} \mathrm{LX}^{\mathrm{a}} \mathrm{IIII}^{\mathrm{a} 111}$.

c) Por lo que se refiere al formulario de los asientos, también se constatan diferencias relevantes con respecto a las adiciones en los libros necrológicos anteriores en el tiempo y a las restantes que conforman el propio Obituario 3.

Son más complejos los apuntes. Al notificativo obiit característico de las adiciones en este tipo de libros, se incorpora el no menos significativo "requiescit", haciendo referencia a la inhumación en recinto isidoriano (in ecclesia ista). El tenor más frecuente es, pues, el siguiente: notificativo obiit, intitulación precedida de la fórmula de humildad famulus o famula Dei, especificación de que el personaje está sepultado en San Isidoro y el año de fallecimiento (expresado en era hispánica) ${ }^{112}$.

Sirva de muestra la nota necrológica correspondiente a Estefanía, hija de Alfonso VII, en las kalendas iulii:

Obiit famula Dei domna Stephania, filia imperatoris Adefonsi, que requiescit in ecclesia ista. Era $\mathrm{M}^{\mathrm{a}} \mathrm{CC}^{\mathrm{a}} \mathrm{XVIII}{ }^{\mathrm{a} 113}$.

Ocasionalmente, en la intitulación se añaden al nombre del difunto y su filiación o parentesco otros datos biográficos, como en la referida a Zaida, anotación que reproduciremos más adelante.

\footnotetext{
${ }^{110}$ Códice IV, fol. $14 \mathrm{r}$.

${ }^{111}$ Códice III.2, fol. 184 r. Véase a propósito de su epitafio la nota 174.

${ }^{112}$ Son excepcionales los asientos sin expresión de año. Uno es el referido a la reina Elvira, anteriormente transcrito, y el otro corresponde a Zaida.

${ }^{113}$ Códice III.2, fol. 186 r.

«Anuario de Estudios Medievales», 33/1 (2003), pp. 365-415 .- ISSN 0066-5061.
} 
Teniendo en cuenta las anteriores observaciones es evidente que, como señalábamos a propósito del asiento necrológico correspondiente a la infanta Sancha, en el primer cuarto del siglo XIII el artífice gráfico del Obituario 3 no empleó como fuente para la inserción de estas noticias relevantes los libros necrológicos utilizados hasta ese momento por la comunidad de canónigos. Volvemos a plantearnos la pregunta ¿de dónde tomó dicha información? ¿de los epitafios sepulcrales? No olvidemos la constante observación requiescit in ecclesia ista. Responder a la pregunta y saber si, efectivamente, se verificó un traslado al pergamino de datos reflejados en piedra, es hoy muy difícil y ello debido a dos razones: la desaparición de muchos de los epitafios y la existencia de renovationes. La pérdida de inscripciones entorpece gravemente la investigación. Por una parte, debemos conformarnos con transcripciones de los siglos XVI-XVIII que pueden contener errores de interpretación y omisiones ${ }^{114}$. Por otra, ignoramos las características de su escritura ${ }^{115}$, lo que impide una comparación con otros objetos escritos isidorianos para determinar su datación y saber si la materialización del epígrafe tuvo lugar con anterioridad o posterioridad al Obituario 3.

\footnotetext{
${ }^{114}$ Pongamos un ejemplo. Por lo que se refiere a las transcripciones publicadas, las debidas a M. Risco son "la fuente más fidedigna" para reconstruir el texto de las inscripciones funerarias desaparecidas, a juicio de J.M. GARCía LOBO, O.c., p. 418. El mismo M. Risco advertía ên referencia al panteón "están muchos sepulcros de Reyes con sus epitafios, los quales he copiado con mayor diligencia que otros" (O.c., p.148). Sin embargo, la colación de su edición con los letreros conservados pone de relieve algún error. Así, en la lectura del tercer epitafio relativo a la infanta Sancha, hermana de Alfonso VII (M. RISCO, O.c., p. 151) confunde la $U$ inicial, ancha, de Urracha con la vocal $O$ (error que no cometen otros lectores). Este fallo no tiene mayor trascendencia pero ¿y si se ha producido alguna anomalía en la transcripción de fechas? Por lo que se refiere a las omisiones, no recoge $M$. Risco el texto del epitafio sencillo que se sitúa en la cabecera del sepulcro de la infanta, letrero que, como hemos señalado anteriormente, podría constituir la primera versión en piedra de la noticia necrológica. También omite Risco en su lectura del epitafio de Sancho el Mayor de Navarra el apelativo "Magno" que precede al nombre de su hijo Fernando I y corrige la data recogida en la tapa del sarcófago, incorporando en la transcripción una $X$ más.

${ }^{115}$ No son fiables las observaciones que, a propósito de la escritura, recogen algunos eruditos que se ocuparon de los epitafios. Sirvan de ejemplo las siguientes observaciones presentes en A. de YEPES, O.c. Se advierte que el sepulcro de Sancho III el Mayor es "gótico" (p. 339), el de la reina Elvira "de letra longobarda que usaron los godos" (p. 339), el de Vermudo II "de letra gótica" (p. 338) y el de Vermudo III "en letra de aquellos tiempos" (p. 339). La aplicación del adjetivo "gótico" a la escritura de los epitafios referidos a dos de los reyes citados, de los cuales conservamos fragmentos con caracteres pregóticos o gótico-primitivos, sorprende, pues es el mismo calificativo utilizado para caracterizar la letra del monumentum aedificationis que se encuentra ahora sobre la puerta tabicada de acceso a la iglesia desde el Panteón de los reyes (Ibídem, p. 339), lápida con texto en escritura visigótica.
} 
La ejecución de renovationes ${ }^{116}$, admitida por varios investigadores ${ }^{117}$, supone un obstáculo ¿Reproducen éstas los textos de los epitafios previos o se redactan enteramente de nuevo? J.I. Gil Pulido afirma que "los numerosos errores históricos y las noticias de origen cronístico"

\begin{abstract}
descartan a nuestro juicio toda posibilidad de que el grupo de epitafios que hemos examinado proceda de las primitivas sepulturas y nos induce a pensar que fueron redactados de nuevo en el momento de la renovación (...) Yo creo que hay que ver este conjunto de epitafios simplemente como monumentos tardíos realizados seguramente en un momento en el que habrían desaparecido los sepulcros originales en algunas de las muchas transformaciones que sufrió la colegiata durante los siglos XI y XII. Ante la imposibilidad de reproducir los epitafios originales, posiblemente se utilizó como fuente una o más crónicas, sin que pueda excluirse otro tipo de textos ${ }^{118}$.
\end{abstract}

Para V. García Lobo, los textos

han sido redactados posteriormente sobre la base de otro anterior del que conservan lo esencial —notificación, intitulación y data- ${ }^{119}$

\title{
y según A. Viñayo González
}

es de suponer que no variarían los textos ${ }^{120}$.

\begin{abstract}
116 "En San Isidoro identificamos al menos siete inscripciones de este tipo. Son los epitafios de Bermudo II, de Alfonso V, de Bermudo III, del conde don García, de Sancho el Mayor, de doña Elvira y de la reina Sancha (éste a juzgar por el pequeño fragmento que se conserva)" (V. GARCÍA LOBO, Las inscripciones, p. 387).

${ }^{117}$ Recojamos la argumentación en contra de J. Pérez Llamazares: "Aunque el Sr. Gómez Moreno propende a defender que en el siglo XII se hizo una reforma general en la capilla de los Reyes y que los sepulcros y sus epitafios se renovaron en esa ocasión al terminar la fase de ampliaciones que él se forjó en su fantasía, esto no es admisible en ningún sentido, pues de haber tal reforma se hubieran hecho iguales todos los sepulcros, y no es así" (J. PÉREZ LLAMAZARES, Historia, p.389). La heterogeneidad de los sepulcros no es incompatible con una "renovatio". En palabras de J.I. GIL PULIDO, O.c., p. 403: "Admitida la renovación, debemos señalar que existe la posibilidad de que no fuera realizada de una sola vez; la diferencia en los materiales y en la tipología de las cubiertas entre las que tienen figura grabada y las que no la tienen quizá nos estén señalando diferencias en el tiempo, si las hubo, a la vista de la semejanza que presentan en la escritura, no debieron ser considerables".
\end{abstract}

${ }^{118}$ J.I. GIL PULIDO, O.c., pp. 409-411.

${ }^{119}$ V. GARCíA LOBO, Las inscripciones, p. 387.

${ }^{120}$ Cf. A. Viñayo GonZÁleZ, Fernando I, p. 39.

«Anuario de Estudios Medievales», 33/1 (2003), pp. 365-415 .- ISSN 0066-5061 
El segundo problema que plantean las renovationes radica en el momento de su materialización. Datables para Gómez Moreno ${ }^{121}$ y Viñayo González ${ }^{122}$ en el siglo XII, "no excluimos la posibilidad de que fueran realizadas en el XIII", advierte Gil Pulido ${ }^{123}$, y también las sitúa García Lobo en el siglo XIII, pero "no antes del segundo tercio"124. No debe sorprendernos esta divergencia, pues fueron varias - y efectuadas en distintos momentos, como veremos más adelante- las intervenciones epigráficas sobre sepulcros del panteón de los reyes.

Limitémonos, pues, a exponer algunos datos resultado de la comparación entre estas anotaciones obituarias y los correspondientes epitafios sepulcrales - desaparecidos unos, supervivientes otros ${ }^{125}$ - a la espera de que la conclusión del estudio del corpus epigráfico isidoriano arroje nueva luz sobre esta cuestión.

Como punto de partida debemos resaltar un dato fuera de toda duda que permite relacionar estos dos tipos de testimonios escritos funerarios: el redactor y artífice material del Obituario 3 sabe que los personajes citados se encuentran inhumados en el centro usuario del citado libro necrológico. Los doce asientos objeto de interés, a algunos de los cuales ya hemos hecho referencia con anterioridad, corresponden a los reyes Vermudo II, Vermudo III y Sancho III el Mayor de Navarra, las reinas Elvira (esposa de Vermudo II), Sancha (esposa de Fernando I), Urraca (madre de Alfonso VII) y Teresa (esposa de Fernando II); las infantas Urraca y Elvira (hijas de Fernando I), Estefanía (hija de Alfonso VII), el infante García (hijo de Fernando II) y Zaida.

Del epitafio de la reina Sancha sólo sobreviven algunos caracteres de la data ${ }^{126} \mathrm{y}$ los letreros funerarios correspondientes al resto de las féminas anteriormente citadas han desaparecido íntegramente. Por lo tanto, las noticias referidas a estas ocho mujeres que se recogen en el Obituario 3 pueden

${ }^{121}$ Cf. M. GÓMEZ MORENO, Catálogo monumental, p. 214.

${ }^{122}$ Cf. A. VIÑAyo GonZÁleZ, Fernando I, p. 39.

${ }^{123}$ J.I. GIL PULIDO, O.C., p. 403.

${ }^{124} \mathrm{~V}$. GARCÍA LOBO, Las inscripciones, p. 387.

${ }^{125}$ La relación entre estos asientos en el obituario y los epitafios la pusimos de manifiesto hace seis años en Patrimonio cultural II, pp. 104-106 y 305-309.

${ }^{126} \mathrm{Nos}$ referimos a un fragmento de mármol correspondiente a la parte inferior de la tapa de un sepulcro depositado ahora, junto a otras piezas pétreas, bajo uno de los arcos del claustro meridional isidoriano, ante la galería septentrional del mismo. 
considerarse los primeros testimonios escritos isidorianos de sus defunciones. La comparación entre el texto de las ocho notas necrológicas y el de las inscripciones funerarias - según las copias literarias a las que hemos tenido acceso- proporciona los siguientes resultados:

a) Las adiciones obituarias correspondientes a la reina Elvira (nota anteriormente transcrita) y Zaida carecen, sorprendentemente, de la especificación de la era en la que tuvo lugar la muerte ${ }^{127}$. Los letreros funerarios tampoco contenían este dato ${ }^{128}$.

b) En el caso de Zaida, no sólo coincidirían el epitafio y el asiento obituario en la omisión del año ${ }^{129}$, también constatamos grandes similitudes en los datos de filiación y en la redacción de los textos. Ambas fuentes explicitan su relación con el rey Alfonso VI, señalan que su nombre se cambió por el de Isabel cuando fue bautizada y cómo la citada era "filia Benabeth regis Sibilie"130.

La anotación necrológica, dispuesta en el Obituario 3 el 13 de enero (idus ianuarii) dice:

${ }^{127} \mathrm{Al}$ respecto de estas y de otras omisiones de fecha, advierte J.I. Gil Pulido: "inexplicable omisión si se tratara de epitafios originales" (O.C., p. 405).

${ }^{128}$ Por lo que se refiere al epitafio de la reina Elvira, seleccionemos dos copias, una manuscrita y otra impresa. "Hic requiescit Regina domna Geloira, vxor Regis Veremundi" (ASIL. Códice XCI, fol. 84 r). M. RISCO, Iglesia de León, p. 148: "H.R. Regina domna Geloira, uxor regis Veremundi". Pueden verse, asimismo, A. de YEPES, O.c. p.338 y J. MANZANO, O.c., p. 324.

${ }^{129}$ Respecto al epitafio: "No dice el año en que murió, que fue gran descuido del cantero" (A. de YEPES, O.c., p. 341).

${ }^{130}$ Error de origen cronístico, según J.I. GIL PULIDo, O.c., p. 406. Lucas de Tuy, en su Chronicon Mundi, recoge la misma filiación. Alfonso VI accepit "Zaydam filiam Benabet regis Sibilie" (ASIL, Códice XX, fol. 111 v), "filiam regis Benabet" (ASIL, Códice XX, fol. 112 v). ¿Tuvo acceso el redactor del Obituario 3 a la obra histórica del Tudense, canónigo de San Isidoro?. No lo consideramos probable, dada la fecha que proponemos para la confección del libro necrológico y el momento en el que presumiblemente Lucas de Tuy concluyó la redacción de la crónica. El Chronicon Mundi del Tudense fue compuesto "en fecha imprecisa durante un periodo amplio que va desde la época de la reina Berenguela (1197-1217) hasta el año 1236, el de la conquista de Córdoba por Fernando III, episodio que remata todo el trabajo del historiador leonés" (F.J. FERNÁNDEZ CONDE, El biógrafo contemporáneo de santo Martino: Lucas de Tuy, "Santo Martino de León", León, 1987, p.307); "[pa.1236]" (M.C. DíAZ Y DíAZ, Index scriptorum latinorum Medii Aevi Hispanorum, Madrid, 1959, $\mathrm{n}^{\circ}$ 1226, p. 263; "antes de 1236" (cf. J.E. LóPEZ PEREIRA, La aportación hispana a la historiografia latina medieval, "Actas I Congreso Nacional de latín medieval", León, 1995, p.184); "posiblemente antes de 1230" (cf. E. FALQUe, Los manuscritos del Chronicon Mundi de Lucas de Tuy de la Real Colegiata de San Isidoro de León, "Actas del II Congreso hispánico de Latín medieval", I, León, 1988, p. 437). 
Obiit famula Dei regina domna Elisabeht (sic), vxor regis Adefonsi, filia Benabeth regis Sibilie, que ante babtismum Zayda est uocata, que requiescit in ecclesia ista ${ }^{131}$.

\section{Y su epitafio rezaba así:}

Hic requiescit Regina Domna Elisabet, vxor regis Adefonsi, filia Benabeth, regis Siuiliae, quae prius Zayda fuit vocata ${ }^{132}$.

El mismo hecho se observa si comparamos los testimonios escritos alusivos a la defunción de Urraca de Zamora, hija de Fernando I. Recojamos en primer lugar la noticia registrada en el Obituario 3 el 25 de junio (VII kalendas iulii):

Obiit famula Dei sapientissima domna Vrracha, regina de Zamora, que ampliauit ecclesiam istam et multis muneribus ditauit, filia regis magni Fredenandi et Santie regine, que requiescit in ecclesia ista. Era $\mathrm{M}^{\mathrm{a}} \mathrm{C}^{\mathrm{a}} \mathrm{XXX} \mathrm{a}^{\mathrm{a}} \mathrm{VIIII}{ }^{\mathrm{a}}{ }^{133}$.

En cuanto a la noticia funeraria en piedra, nos hallaríamos ante un caso análogo al de los epitafios protagonizados por la infanta Sancha, hermana de Alfonso VII. En un texto laudatorio ${ }^{134}$ - de compleja redacción versificada ${ }^{135}$ - se intercalaría el siguiente epígrafe, más fácil de interpretar $\mathrm{y}$, pensamos, realizado varios años después:

${ }^{131}$ Códice III.2, fol. $182 \mathrm{r}$.

${ }^{132}$ Texto recogido en ASIL, Códice XCI, fol. 85 v. "H.R. Regina Domna Elisabeth, uxor Regis Alfonsi, filia Benabet Regis Siviliae, quae prius Zaida fuit vocata" (M. RisCO, O.c., p. 151). Con pocas variantes gráficas en P. DE SANDOVAL, O.C., fol. $90 \mathrm{v}$ y en las restantes ediciones.

${ }^{133}$ Códice III.2, fol. $186 \mathrm{r}$.

${ }^{134}$ Que era especialmente querida en San Isidoro se pone también de relieve en las características de su sepulcro "su sepulcro es extrañamente ríco" (cf. A. de MORALES, O.c. p.44). "...el arca de mármol blanco, muy exçellente la cubierta, en que está a la larga el epitaphio, es tumbada y de aquel pórfido morado..." (ASIL, Códice X'CI, fol. 86 v). "La sepultura quarta de las altas del segundo orden. En la cubierta della, que es una gran piedra de jaspe..." (ASIL, Códice XCIV, fol. 78 v del segundo libro).

135 "Nobilis Urraca jacet hoc tumulo tumultata: Hesperiaeque decus heu! tenet hic loculus. Haec fuit optandi proles Regis Fredenandi. Ast Regina fuit Sanctia quae genuit. Centies undecies sol volverat, et semel annum, carne quod obtectus sponte" (M. RISCO, O.c., p. 150). Optamos por la edición de M. Risco, más clara, porque en el Códice XCI, fol. $86 \mathrm{v}$, y en otras copias literarias los dos epitafios aparecen intercalados. 
H.R. Domna Urraca Regina de Zamora, Filia Regis magni Fernandi. Haec ampliavit Ecclesiam istam et multis muneribus ditavit. Et quia Beatum Isidorum super omnia diligebat, ejus servitio subjugavit. Obiit Era MCXXXVIIII $^{136}$

El letrero en prosa y la anotación del Obituario 3 son, como se advierte inmediatamente, muy parecidos.

c) Las notas necrológicas del Obituario 3 anteriormente transcritas relativas a la reina Teresa, esposa de Fernando II y a la infanta Estefanía, hija de Alfonso VII, cuyos fallecimientos tuvieron lugar cuando ya se encontraban en San Isidoro de León los canónigos regulares, coincidirían en los datos cronológicos con las correspondientes inscripciones funerarias. Los epitafios, sin embargo, son más amplios que los asientos de libro.

La inscripción alusiva a la reina Teresa es versificada

Larga manus miseris, et dignis digna rependis.

Constans, et prudens pietatis munere splendens,

Hic Regina jacet coniux Taresia Regis.

Era MCCXVIII et qott. VII. Id. Februariii ${ }^{137}$.

\section{Y la correspondiente a la infanta Estefanía}

Hic requiescit infantissa Domina Stephania, filia imperatoris Adefonsi, coniux Fernandi Roderici potentissimi varonis, mater Petri Ferdinandi Castellani, quae obiit Era MCCXVIII kalendas Iuliii ${ }^{138}$.

d) Notablemente más extenso que el asiento necrológico correspondiente, es el epitafio de la reina Sancha, esposa de Fernando I. Sin embargo, a diferencia de lo constatado en los ejemplos anteriores, se observaría una discordancia en la especificación de fecha entre la anotación obituaria y la inscripción. El letrero del sepulcro rezaría

${ }^{136}$ M. Risco, O.c., p. 150.

${ }^{137}$ M. RisCo, O.C., p. 152. No coincide el día y el mes con el señalado por J. González Martínez: "Doña Teresa murió pronto, el 5 de marzo de 1180" (J. GoNZÁLEZ MARTíNEZ, Reyes y reinas de León en vida de santo Martino, "Santo Martino de León", León, 1987, p. 117). La copia del epitafio que figura en el Códice XCI, fol. 87 r, omite la especificación del día y mes en el que tuvo lugar el fallecimiento de la reina.

${ }^{138}$ ASIL, Códice XCI, fol. 86 v. En lectura de M. Risco, O.c., p. 152: "H.R. Infantissa Domna Stephania, filia Imperatoris Adefonsi, conjux Ferdinandi Roderici potentissimi Baronis, mater Petri Ferdinandi Castellani, quae obiit Era MCCXVIII kal. Julii".

«Anuario de Estudios Medievales», 33/1 (2003), pp. 365-415 .- ISSN 0066-5061 
H.R. Sancia Regina totius Hispaniae, magni Regis Fernandi uxor, Filia Regis Adefonsi, qui populavit Legionem post destructionem Almanzor. Obiit Era MCVIIII. III ${ }^{\circ}$. N.M ${ }^{139}$.

Aunque actualmente sólo contamos con un fragmento que recoge el final del epígrafe ([..]IIII. III ${ }^{\circ}$ NONAS. M) ${ }^{140}$. En el Obituario 3, III nonas marcii, leemos:

Obiit famula Dei Regina domna Sancia, vxor regis magni Fredenandi que requiescit in ecclesia ista. Era $\mathrm{M}^{\mathrm{a}} \mathrm{C}^{\mathrm{a}} \mathrm{VIII}^{\mathrm{a}}{ }^{141}$.

También en la expresión de la data - en este caso día, mes y añoradicaría la principal divergencia interna entre la anotación obituaria relativa a la infanta Elvira, hija de Fernando I, y sus epitafios ahora desaparecidos. La memoria de doña Elvira se asocia en el Obituario 3 al 25 de marzo (VIII kalendas aprilis) del año 1092:

Obiit f $a \mathrm{~m} u \mathrm{la}^{142}$ Dei infantissa domna Geloira, filia regis magni Fredenandi, que requiescit in ecclesia ista. Era $\mathrm{M}^{\mathrm{a}} \mathrm{C}^{\mathrm{a}} \mathrm{XXX}^{\mathrm{a} 143}$.

Sin embargo, la defunción de doña Elvira se fija epigráficamente el 15 de noviembre de 1101, fecha mencionada en el siguiente epitafio versificado, muy elogioso:

Vas fidei, decus Hesperiae, templum pietatis, Virtus justitiae, sidus, honor patriae.

Heu quindena dies mensis, Geloira, novembris.

Exilium multis, te moriente, fuit.

Annis mille VIIII CXXX, peractis

${ }^{139}$ Elegimos en este caso la transcripción de M. Risco porque, ajustándose con mayor fidelidad al epígrafe, mantiene con la sigla $M(O . c ., \mathrm{p} .150)$ la expresión del mes. Otras copias desarrollan la abreviatura en maii (ASIL, Códice XCII, fol. $85 \mathrm{r}$, P. de SANDOVAL, O.c., p. 19r, J. ManZano, O.c., p. 348), resolución que acepta J.I. Gil Pulido, O.c., p. 405. Este investigador llama la atención, asimismo, sobre el que considera "error cronológico en el epitafio" al advertir la discordancia con respecto a las otras fuentes que han recogido la noticia.

${ }^{140}$ Véase la nota 126.

${ }^{141}$ Códice III.2, fol. $184 \mathrm{r}$.

${ }^{142}$ Enmienda autocorrectora, bajo la $a$ final hay una $s$.

${ }^{143}$ Códice III.2, fol. 184 v.

«Anuario de Estudios Medievales», 33/1 (2003), pp. 365-415 .- ISSN 0066-5061. 
Te tua mors rapuit, spes miseros latuit ${ }^{144}$.

En este letrero se insertaría otra inscripción posterior, muy escueta, en $\operatorname{prosa}^{145}$ :

H. Re. Domna Geloira, filia Regis magni Fernandi ${ }^{146}$.

De los epígrafes sepulcrales relativos a siete de las mujeres anteriormente citadas no se conservan, decíamos, restos materiales. De los correspondientes a Vermudo II, Vermudo III, Sancho el Mayor de Navarra y al infante García, perduran, como consignábamos a propósito de la reina Sancha, sólo fragmentos. Por lo que se refiere al epitafio de Vermudo $\mathrm{II}^{147}$, sobrevive el texto siguiente:

\section{[...]VDVS ORDONII $\uparrow$ ISTE IN FINE VITE SUE DIGNA DEO PE[.......] PACE QVIEVIT ERA MXXXVII[... $]^{148}$.}

Y de la inscripción alusiva a Vermudo III $^{149}$ sólo se conserva la notificación del enterramiento y la intitulación:

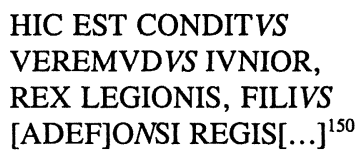

\section{${ }^{144}$ M. RISCO, O.c., p. 151.}

${ }^{145}$ Varias de las copias literarias, como la que se localiza en el Códice XCI, fols. 86 v-87 r, reproducen los textos de ambos letreros entremezclados.

${ }^{146} \mathrm{Ibi}$ dem.

${ }^{147}$ El epígrafe se dispone en fragmentos de una lápida de mármol negro desplazada de su lugar originario y fijada ahora al muro oeste de la capilla de Santa Catalina, sede del panteón real.

${ }^{148}$ Puede completarse con la transcripción que proporciona M. RisCo, O.c., p. 148: [H.R. Verem]VDVS ORDONII + ISTE IN FINE VITE SUE DIGNAM DEO P[oenitentiam obtulit et in] PACE QUIEVIT ERA MXXXVII. Salvo alguna variación gráfica de poca importancia, coincide con el texto copiado en el Códice XCI, fol. $84 \mathrm{r}$.

${ }^{149} \mathrm{Se}$ trata de un fragmento de la tapa del sepulcro fijado al muro oriental del primer claustro. La reproducción fotográfica del epitafio en V. GARCíA LOBO y E. MARTíN LÓPEZ, De epigrafia medieval, lámina XXXI, p. 55.

${ }^{150} \mathrm{La}$ lectura de M. Risco es la siguiente: "Hic est conditus Veremudus junior, Rex Legionis, filius Adefonsi regis. Iste habuit guerram cum cognato suo Rege magno Fredenando et interfectus est ab illo in Tamara praeliando. Era $\operatorname{MLXXV"~}^{\prime}$ O.c., p.149). El texto del letrero, con pocas variantes, en el Códice XCI, fol. 85 v. 
Completando la lectura con sus copias literarias, parece ser que ambos letreros carecían de especificación de día y mes, datos que en las adiciones obituarias propiamente dichas no son necesarios, pues éstas ya se adscriben a un determinado día del calendario ${ }^{151}$. En cuanto al año de la defunción, coinciden el texto en pergamino y el texto en piedra. El formulario de unas $\mathrm{y}$ otras fuentes difiere notablemente, transmitiendo las inscripciones mayor número de datos. Por lo que se refiere a los caracteres externos, la escritura de los epígrafes funerarios de los dos reyes es -como constatamos también en el fragmento del letrero correspondiente a la reina Sancha- muy posterior al año de fallecimiento ${ }^{152}$. Los signos presentan analogías con los publicitarios que se hallan tanto en el Obituario 3 como en otros manuscritos isidorianos datados entre finales del siglo XII y el primer cuarto del XIII.

Caso bien distinto lo constituye otra inscripción conservada fragmentariamente en el recinto isidoriano, la correspondiente al infante García, hijo de Fernando II, cuya escritura - carolina evolucionada - parece ser coetánea al momento del fallecimiento. Recojamos en primer lugar la adición que en el Obituario 3 encabeza las memorias del 12 de febrero (II idus februarii):

Obiit famulus Dei <infans> Garssias, Fernandi regis filius, qui requiescit in ecclesia ista. Era $\mathrm{M}^{\mathrm{a}} \mathrm{CC}^{\mathrm{a}} \mathrm{XX}^{\mathrm{a}} \mathrm{II}^{\mathrm{a}}{ }^{153}$.

Esta nota necrológica es la que permite atribuir al hijo de Fernando II una tapa de sepulcro mutilada que, desplazada de su ubicación inicial, aparece ahora fijada al muro oriental del claustro meridional, próxima a la puerta de acceso a la capilla "de los Omañas". El letrero que porta, dispuesto en un renglón que sigue el eje longitudinal de la pieza, reza así:

[HIC REQVIESCIT FAMVLVS DEI GAR]SIA, FERNANDI REGIS FILIVS, QVI OBIIT ERA $\mathrm{M}^{\mathrm{a}} \mathrm{CC}^{\mathrm{a}} \mathrm{XX} \mathrm{II}^{154}$.

\footnotetext{
${ }^{151}$ No podemos descartar, sin embargo, que tales especificaciones pudieran aparecer en algún letrero secundario o complementario no recogido por Risco, pues tampoco transcribió el sencillo epígrafe que hoy podemos leer en la cabecera del sepulcro de la infanta Sancha.

${ }^{152}$ Estas inscripciones son, por ello, renovationes para V. GARCÍA LOBO, Las inscripciones, p.387. La relativa a Vermudo III es considerada, asimismo, una "Ampliatio del siglo XIII" por V. GARCÍA LOBO y E. MARTÍN LóPEZ, De epigrafía medieval, p. 55.

${ }^{153}$ Códice III.2, fol. $183 \mathrm{r}$.

${ }^{154} \mathrm{La}$ transcripción de M. Risco en O.c., p. 152. 
Ambos textos, escuetos, reproducen la misma intitulación y coincide el año de fallecimiento consignado. Por lo que se refiere a las especificaciones de día y mes, sirva lo advertido a propósito de los epitafios de Vermudo II y Vermudo III.

Para cerrar esta comparación entre las adiciones verificadas en el Obituario 3 y los epitafios, incorporamos al análisis una lauda sepulcral mutilada que, además, se encuentra actualmente repartida en dos recintos. Aproximadamente la mitad superior de la pieza se halla depositada en el Museo de León $n^{155}$ y el fragmento que corresponde a los dos tercios izquierdos de su mitad inferior permanece en San Isidoro, apoyado en el muro este del claustro meridional. Si unimos los dos fragmentos, que presentan escritura evolutivamente similar a la de los epitafios de Vermudo II y Vermudo III, hallamos el siguiente letrero ${ }^{156}$ :

\section{†HICSITVS EST SANCIVSREX PIRENEORVM MONCIVMET TOLOSE, UIR [...] $]^{157}$ TRANSLATVS EST HIC A FILIO SVO ${ }^{158}$ [R]EGE MAGNO FERNANDO. OBIIT ERA MaLX[...].}

Se refiere la inscripción a Sancho III el Mayor de Navarra ${ }^{159}$. En el fragmento isidoriano, tras el último carácter gráfico superviviente -la $X$ de $L X-$, se sitúan los tres puntos dispuestos en línea vertical que el artífice del epígrafe emplea para separar palabras, como si la especificación de las décadas se hubiese dado por concluida. Esta triple interpunción precede a los rasgos iniciales de una letra que, evidentemente, no es una $X$ y sí, probable-

${ }^{155}$ Cf. L. GRAU, Lauda sepulcral de Sancho III de Navarra, "Maravillas de la España medieval. Tesoro sagrado y monarquía. I. Estudios y catálogo", Madrid, 2000, p. 145 (Procedencia: Villanueva del Carnero (León), originariamente en San Isidoro de León. Museo de León").

${ }^{156}$ Basándose en los caracteres internos, J. PÉREZ DE ÚRBEL, Sancho el Mayor de Navarra, Madrid, 1950, p.230 cree que el epitafio se realizó "lo más pronto a finales del siglo XII". L. GRAU, O.c., p. 145 considera la pieza de "principios del siglo XIII" y V. GARCíA LOBO y E. MARTÍN LÓPEZ, O.c., p. 54, "del siglo XIII"

${ }^{157}$ Uir per omnia Catholicus et pro Ecclesia (M. RisCo, O.c., p. 149).

${ }^{158}$ El texto HIC SITUS EST SANCIUS REX PIRENEORUM MONCIVM ET TOLOSE, UIR [...] TRANSLATUS EST HIC A FILIO SVO [...] se halla en el fragmento custodiado en el Museo de León.

${ }^{159} \mathrm{~A}$ propósito del texto del epitafio advierte J. PÉREZ DE ÚRBEL, O.c., p.230: "No es necesario perder tiempo en demostrar que esta inscripción encierra una superchería semejante a la que ya conocemos del sepulcro del infante García". V. GARCÍA LOBO, La epigrafía medieval, p. 103, considera falsa la inscripción. 
mente, una $I$. Cuando M. Risco leyó el letrero, figuraría, según él, la siguiente fecha íntegra:

\section{Era MLXXIII ${ }^{160}$.}

pero tal lectura no es admisible, teniendo en cuenta los restos de epitafio. $M$. Risco efectuó, consciente o inconscientemente, una corrección en la era expresada $^{161}$. En lo que atañe a la especificación de fecha, se demuestra, por tanto, más fiel al letrero funerario sobre piedra la copia recogida en el Códice $\mathrm{XCI}$ isidoriano:

Hic situs est Sanctius, Rex Pyreneorum montium et Tolosae, vir per omnia catholicus et pro ecclesia translatus est hic a filio suo rege magno Fernando, obiit era MLXIII ${ }^{162}$.

Una adición inserta en el Obituario 3, el 11 de junio (III idus iunii), se refiere también al padre de Fernando I:

Obiit famulus Dei Santius, rex Cantabrie, qui translatus est in ecclesiam istam a filio suo rege magno Fredenando. Era $M^{a} L^{a} I^{a}{ }^{163}$.

La única disimilitud relevante que pone de manifiesto el cotejo entre la adición obituaria y el epitafio se halla en la intitulación ${ }^{164}$, pues ambos escritos comparten la transmisión de una fecha anómala.

${ }^{160}$ Cf. M. RISCO, O.C., p. 149.

${ }^{161}$ Es 1035 el año del fallecimiento (cf. J. PÉREZ DE ÚRBEL, O.c., p. 228). Al igual que Risco, señalan la era 1073 otros editores como A. de LOBERA, O.c., fol. $325 \mathrm{v}$ o J. MANZANO, O.c., p.334, así como la copia que recoge el Códice XCII, fol. $32 \mathrm{v}$.

${ }^{162}$ Códice XCI, fol. $84 \mathrm{v}$.

${ }^{163}$ Códice III.2, fol. $185 \mathrm{v}$.

${ }^{164}$ La especificación rex cantabri se ajustaría a las recogida en crónicas. Es el caso de la historia silense (Historia silense (edición crítica e introducción de J. PÉREZ DE URBEL y A. GONZÁleZ RuIZ-ZORRILlA, Madrid, 1959, p.181) y del Chronicon Mundi de Lucas de Tuy: "Sancius autem rex Cantabriensium" (ASIL, Códice XX, f.100v). Ambos textos se hallan muy vinculados al recinto isidoriano. La crónica silense tiene datos hasta 1109 y "cada vez son más los que piensan que salió del monasterio de San Juan de León, más tarde San Isidoro" (J.E. LÓPEZ PEREIRA, O.c., p. 184); "Se escribió o en San Isidoro de León o muy cerca de él" (A. VIÑAYO GONZÁLEZ, El scriptorium medieval del monasterio de San Isidoro de León y sus conexiones europeas, "Circulación de códices y escritos entre Europa y la Península en los siglos VIII-XIII", Universidad de Santiago de Compostela, 1988, p. 220. Véase a propósito del Chronicon Mundi la nota 130

«Anuario de Estudios Medievales», 33/1 (2003), pp. 365-415 .- ISSN 0066-5061. 
Establecida la comparación entre ambos tipos de fuentes, retomemos la pregunta anteriormente planteada: ¿Tomó el artífice del Obituario 3 datos recogidos en piedra?. En algunos casos, tal vez sí. La escritura del epitafio versificado de la infanta Sancha y de los correspondientes al prior Pedro Arias y al abad Menendo podrían indicar que los letreros en verso se ejecutaron en la segunda mitad del siglo XII y son, por lo tanto, anteriores al tercer obituario. Uno de los epitaphia sepulcralia en verso, hoy desaparecido, se disponía, como hemos señalado anteriormente, en el sarcófago de la infanta Elvira. La expresión de la era, alterado el orden de los numerales con fines poéticos (VIIII $C X X X)^{165}$, podría explicar que el artífice del Obituario 3 reprodujese erróneamente el año de fallecimiento de la infanta, adelantando el suceso nueve años (era $M C X X X)^{166}$. En otros casos, es significativa la coincidencia entre las noticias en piedra y las transmitidas en pergamino: omisiones de datos (información sobre la reina Elvira y Zaida), errores (Sancho III el Mayor) o redacción de los textos (Zaida y Urraca de Zamora). Sin embargo, desaparecidos los epitafios de las tres mujeres citadas resulta imposible saber si se ejecutaron con anterioridad a la elaboración del Obituario 3 o si son posteriores al libro necrológico.

En definitiva, no podemos excluir el traslado de datos de la piedra al pergamino, es decir, el recurso - por parte del artífice del Obituario 3- a fuentes epigráficas para la obtención de información. Tal hecho no se hallaría en el origen de la totalidad de las anotaciones obituarias referidas a los miembros de la familia real inhumados en recinto isidoriano, como ponen de manifiesto algunas disimilitudes sobre las cuales hemos llamado anteriormente la atención. Por otra parte, aun en los casos en los que se advierten significativas coincidencias, nunca son las adiciones en el libro necrológico copia textual de los correspondientes letreros sepulcrales.

\footnotetext{
${ }^{165}$ Alteración que se mantiene en algunas copias literarias del epitafio. En otras, sin embargo, se corrige la disposición de los numerales (sirva dẹ ejemplo P. de SANDOVAL, O.c., fol. $92 \mathrm{v}$ ).

${ }^{166}$ Para la discordancia en día y mes no hallamos explicación alguna. Véase, no obstante lo que advertimos al final de este estudio sobre la adscripción de óbitos a determinados días del calendario.

«Anuario de Estudios Medievales», 33/1 (2003), pp. 365-415 .- ISSN 0066-5061.
} 


\section{DE PIEDRAS Y PERGAMINOS}

¿A dónde nos ha conducido este recorrido por los monumentos gráficos isidorianos relacionados de un modo $\mathrm{u}$ otro con la muerte entre mediados del siglo XII y el primer cuarto de la centuria siguiente? Son varias las conclusiones que podemos fijar como punto de partida para nuevos estudios sobre el patrimonio escrito isidoriano y para la aproximación histórica a numerosas figuras - de los siglos X-XII- relacionadas de algún modo con la Real Colegiata.

1. En San Isidoro de León el periodo comprendido entre mediados del siglo XII y el primer cuarto del siglo XIII es rico en producción escrita de carácter funerario en pergamino y en piedra. Creemos conveniente diferenciar dos etapas: la segunda mitad del siglo XII y un corto intervalo en el primer cuarto del siglo XIII, a partir de 1210.

Por lo que se refiere a la segunda mitad del siglo XII, y centrándonos primeramente en los pergaminos, es, aproximadamente, 1150 el año en el que se inician los asientos en los dos obituarios vivos de la canónica regular isidoriana (Obituarios 1 y 2 ). Con el adjetivo vivo -extraño calificativo para un libro necrológico- queremos señalar que son éstos registros cuyo proceso de génesis es muy largo, puesto que a ellos se van incorporando asientos a medida que se producen los óbitos que recuerdan.

Fenómeno análogo se advierte en el campo de los epitafios. Las inhumaciones verificadas en el recinto de la Real Colegiata conllevan la ejecución paralela de inscripciones funerarias. Realizados estos epígrafes con poca posterioridad al momento de los enterramientos, forman, como ocurre en el caso de los asientos necrológicos en los obituarios, un conjunto muy heterogéneo en la preparación del soporte, el tipo de piezas - basas, sillares de muro, tapas de sepulcro, etc.-, la disposición del texto y la escritura. Sin embargo, junto a esta producción epigráfica escalonada en el tiempo, que podemos calificar de básica, imprescindible u ordinaria, asociada a los enterramientos que se van sucediendo en el periodo, parece desarrollarse otra empresa de duración más breve - probablemente en el último cuarto de la centuria- y objetivo perfectamente definido: la ejecución de epitafios correspondientes a personajes de relieve enterrados en el recinto isidoriano, algunos de los cuales fallecieron con notable anterioridad al establecimiento en él de la comunidad de canónigos regulares de San Agustín. La desaparición de buena parte del patrimonio escrito en piedra de la Real Colegiata y la ausencia de otras fuentes isidorianas nos impide saber si tales letreros se 
dispusieron sobre los sepulcros primitivos anepigráficos o se grabaron en sarcófagos de nueva cuña, si los artífices se limitaron a transliterar epitafios anteriores u obraron con entera libertad en la redacción de los textos. No podemos desligar estas acciones de las otras manifestaciones escritas isidorianas, la dignificación de los letreros funerarios discurre paralela a las labores desarrolladas en el scriptorium librario vinculado a la canónica en una etapa muy próspera. La preocupación por crear objetos escritos bellos es, en algunos casos, evidente, propósito que se logra epigráficamente plasmando sobre superficies perfectamente estructuradas, con letras armoniosas, textos en verso, aun cuando éstos resulten de difícil interpretación.

En el primer cuarto del siglo XIII, no antes de 1210, se detecta otra fase muy activa, y de corta duración, en la producción escrita funeraria isidoriana en piedra y en pergamino. Las labores escriptorias en este momento no son neutrales, el objetivo no es únicamente proporcionar noticias necrológicas, transmitir datos, alimentar el recuerdo piadoso... Se observa otra intencionalidad en la información: llamar la atención sobre el Panteón Real, poner de relieve que San Isidoro de León fue elegida como lugar de enterramiento por varios monarcas y sus familiares desde el siglo $\mathrm{X}$. ¿Reivindica la canónica isidoriana esplendores pasados en un momento en el cual comienza a producirse un estancamiento o incluso un declive en su economía, su vida comunitaria y su actividad cultural? ${ }^{167}$ ¿Desea resaltar con todos los medios a su alcance la vinculación con la corona? Inhumado ya fuera del recinto isidoriano Fernando II ¿pretende recuperar, frente a otras sedes, su condición de panteón regio? ${ }^{168}$.

Evaluada con ocho siglos de distancia, calificaríamos de excesiva-e, incluso, de innecesaria en ocasiones- esta producción escrita necrológica.

Comencemos refiriéndonos a la producción en pergamino. Circa 1212 se realiza otro obituario, el tercero, cuando el que hemos llamado Obituario 2 - libro que constituye el principal modelo del nuevo- está aún en pleno uso. La ejecución de este Obituario-copia parece justificarse únicamente por el interés en introducir a la relación de memorias las relativas a monarcas y otros miembros de la familia real que se hallan enterrados en el recinto

\footnotetext{
167 "Una de las cualidades que más ennoblece a un monasterio es que hayan elegido los reyes su casa o templo para descansar en él sus cuerpos después que pasaren de esta vida" (A. de YEPES, O.c., p. 336).

${ }^{168} \mathrm{Si}$ este fue el propósito, no se consiguió pues Alfonso IX y su esposa Berenguela, benefactores de San Isidoro de León no se enterraron en su recinto. Remitimos a la nota 86.

«Anuario de Estudios Medievales», 33/1 (2003), pp. 365-415 .- ISSN 0066-5061.
} 
isidoriano, circunstancia que se señala explícitamente (requiescit in ecclesia ista), fallecidos algunos con anterioridad al establecimiento de los canónigos regulares en San Isidoro. Tales asientos hubiesen podido incorporarse al Obituario 2 pero, conteniendo éste ya gran número de adiciones, difícilmente encabezarían la relación de noticias adscritas a un determinado día de calendario. Realizar un obituario de nueva cuña permite que estas notas necrológicas que se pretende resaltar sean las primeras asociadas a un determinado día, con lo que la prelación está ya garantizada. Introducidos estos asientos especiales, el artífice del Obituario 3 procede a copiar los restantes del Obituario $2^{169}$. Este nuevo libro necrológico del siglo XIII tuvo vida efímera, nunca sustituyó al segundo obituario - que se utilizó simultáneamente - y su envergadura material - folios excesivamente grandesresultaba poco adecuada teniendo en cuenta el uso - cotidiano- de este tipo de ejemplares.

La actividad epigráfica presenta grandes similitudes -y no sólo en la escritura publicitaria pregótica- con la ejecución del Obituario 3. Teniendo en cuenta los testigos supervivientes de estas tareas, podemos deducir que fueron dos las acciones desarrolladas. Por una parte, se llevan a cabo renovationes en sepulcros del Panteón Real, lo que conlleva la ejecución de epitafios nuevos. Por otra, se introducen en sepulcros antiguos más letreros ${ }^{170}$,

\footnotetext{
${ }^{169}$ Nos preguntamos en otra ocasión (Patrimonio cultural II, p.106) cuál pudo ser la razón que impulsó la realización de este Obituario cuando se encontraba aún en uso el ya mencionado del Códice IV (ambos Obituarios se usaron simultáneamente durante algún tiempo). Apuntábamos entonces que este documento necrológico es testimonio de un intento de llamar la atención en los primeros años del siglo XIII sobre los monarcas y otros miembros de la familia real que desde el siglo X eligieron el cenobio isidoriano como panteón.

${ }^{170}$ También se efectuaría en este momento el grabado de figuras que representan a los personajes inhumados, de los cuales se conservan varios ejemplos y sabemos de la existencia de otros por notas que acompañan a las copias literarias de los epitafios. Tomando como referencia algunos de los supervivientes, es éste el caso de las lápidas correspondientes a Vermudo II y Sancho el Mayor de Navarra, las figuras de los reyes son enmarcadas por los respectivos epitafios funerarios. Basándose en los aspectos artísticos, la imagen que representa al segundo de los monarcas citados ha sido datada por la profesora E. Fernández González en la primera mitad del siglo XIII (Lauda sepulcral de Sancho III de Navarra, "O Románico e o Douro", Valladolid, 1998 , pp. 122-124). No se advierte, por tanto, contradicción con las fechas que apuntamos para la escritura. En los dos casos citados nos hallaríamos ante lápidas renovadas cuando se ejecutaron letreros y figuras, aunque no podemos descartar, puesto que se trata de piezas mutiladas, que fueran antiguas cubiertas anepigráficas o con letreros breves y marginales. Sin embargo, también se realizaron figuras y letreros en prosa que las enmarcan sobre lápidas que portaban ya epígrafes destacados por la longitud de su texto y su posición. Fijado ahora al muro este del claustro meridional isidoriano, se halla un fragmento de la tapa del sepulcro de la reina Elvira, esposa de Alfonso V (lo identificamos tomando como base la transcripción de M. RISCO, O.c., p.149). La figura de la reina -enmarcada también por un letrero en prosa, del siglo XIII- se grabó sobre una inscripción anterior que se disponía siguiendo el eje longitudinal de la lauda.
} 
aprovechando la superficie libre del sarcófago - cabeceras, labios de tapa$\mathrm{e}$, incluso, los espacios entre renglones de las inscripciones primitivas. Como resultado de estas labores epigráficas, las cubiertas de ciertos sarcófagos se encuentran completamente tapizadas con letras y algunas portan epitafios intercalados o entremezclados y, a primera vista, desconcertantes. Si en la segunda mitad del siglo XII la belleza externa e interna de los epígrafes parecía ser un objetivo, en esta etapa se busca, sin embago, la claridad en la redacción -inscripciones en prosa cuyo propósito parece ser a veces explicitar los letreros versificados anteriores, de adscripción confusa- y la ampliación de la información, introduciendo en el texto mayor número de datos biográficos.

2. En el recinto isidoriano no se duplica la información.

Son evidentes, e inevitables, las relaciones entre los distintos tipos de objetos escritos - cartas de donación justifican asientos en los libros necrológicos- pero no hallamos en el periodo objeto de estudio piezas que muestren una copia literal de los mensajes funerarios.

Por lo que se refiere a la relación obituario/epitafio necrológico ¿Cómo explicar la ausencia en San Isidoro de León de un "obituario en piedra" de mayor o menor envergadura?.

Tal vez la comunidad isidoriana consideró innecesario reproducir noticias estrictamente necrológicas en dos tipos de objetos escritos diferentes, teniendo en cuenta por una parte los destinatarios de la noticia y, por otra, la duración que se pretendía tuviera dicha información. Expliquemos brevemente ambos aspectos.

Los obituarios suelen formar parte de un volumen más complejo -el liber capituli- imprescindible en el oficio litúrgico de Prima ${ }^{171}$. La obligada lectura en voz alta del necrologio y, en concreto, de los asientos correspondientes al día en cuestión, hace que los miembros de la comunidad conozcan ya desde el inicio de cada jornada los nombres de las personas encomendadas a su oración. Los destinatarios de la noticia necrológica stricto sensu son los canónigos isidorianos, participantes en el oficio de Prima; el obituario cubre, pues, sobradamente, esta necesidad informativa.

Por lo que se refiere al segundo aspecto, la pretendida duración de la información, quizá la ausencia de epígrafes necrológicos no responda exclusivamente al afán por evitar duplicaciones $-\mathrm{y}$ economizar así en

\footnotetext{
${ }^{171}$ Tipo de libro del cual el Códice IV del archivo isidoriano constituye buena muestra.
} 
soportes, esfuerzo y espacios - y se deba al distinto carácter o finalidad que se adjudica a los dos objetos escritos. Los obituarios tienen, no lo olvidemos, un cierto tinte administrativo; la inclusión en ellos de algunas personas ajenas a la canónica - lo hemos puesto de manifiesto anteriormente- responde a su condición de benefactores pero, cuando se agotan las cantidades en metálico $\mathrm{u}$ otros bienes perecederos entregados para sufragar la celebración de aniversarios ¿puede suprimirse el nombre del donante? Los obituarios 1 y 2 presentan espacios en blanco debidos al raspado de adiciones. Tal posibilidad sólo es factible sobre pergamino, mucho más difícil -o imposible - sería eliminar los caracteres grabados en piedra. No olvidemos que el libro en pergamino garantiza una cierta durabilidad pero no la absoluta pervivencia de los caracteres gráficos y el propósito de la inscripción es, por el contrario, asegurar la permanencia de lo escrito.

En cuanto a la relación obituario-epitafio sepulcral, advertimos que un asiento en los obituarios vivos (obituarios 1 y 2) y la inscripción referida al difunto se originan en el mismo hecho luctuoso y constituyen expresiones escritas paralelas de la noticia, pero no son copia una de la otra. Sólo detectamos algún ejemplo en el que una adición obituaria pudo servir para ampliar con cierta posterioridad un epígrafe sepulcral.

Mayores problemas plantea establecer cuál es la relación entre el Obituario 3, libro-copia, y los epitafios sepulcrales de ciertos miembros de la familia real, personajes que figuran en el libro necrológico con la observación requiescit in ecclesia ista. Descartada en todo caso la existencia de copias literales, ciertos asientos del libro permiten suponer un transvase de información de la piedra al pergamino y otros muestran una independencia neta de los correspondientes epitafios (evidentes divergencias observables fundamentalmente en intitulaciones y datas). No podemos descartar, asimismo, que ciertas entradas en el Obituario 3 y los epígrafes sepulcrales relativos a las mismas personas sean independientes entre sí pero ligados a una fuente común que desconocemos ¿un manuscrito de carácter histórico, una crónica? ${ }^{172}$ ¿un libro de sepulturas? ${ }^{173}$.

\footnotetext{
${ }^{172}$ Remitimos a las notas 98,130 y 164.

${ }^{173}$ ¿Contó la comunidad isidoriana con un "libro de sepulturas"? Lo ignoramos, aunque no podemos descartar su existencia, sobre todo si antes de la ejecución de letreros en el periodo objeto de estudio los sepulcros eran anepigráficos o sustentaban letreros poco explícitos. Según N. HUYGHEBAERT (O.C., pp. 71-73), los libros de sepulturas se justificarian porque, con ocasión del aniversario de un difunto, frecuentemente se realizaba una visita a la tumba. Era, por tanto, necesario anotar el emplazamiento de cada sepultura y el nombre de los difuntos que reposaban 
3. Puesto que no se observa duplicación de los mensajes, los tres tipos de objetos escritos analizados son complementarios y como tales han de ser utilizados. Diplomas, obituarios y epitafios deben tenerse en cuenta conjuntamente cuando se pretenda un estudio histórico serio de la historia de la Real Colegiata y de los personajes relacionados de algún modo con ella, aun cuando, como observamos al comparar ciertas inscripciones funerarias y los correspondientes asientos en libros necrológicos, se adviertan divergencias en la especificación de la data cronológica.

Como hemos demostrado, las ventajas de la utilización simultánea de documentos, epitafios e inscripciones son múltiples. Un diploma - pieza con datación explícita- sirve para fechar por aproximación una nota necrológica de obituario, teniendo en cuenta que estas adiciones habitualmente no explicitan el año del fallecimiento; datos relativos a una persona y reflejados en su epitafio completan los recogidos en el obituario, y viceversa; la interpretación de una inscripción sepulcral versificada se ve facilitada por las sobrias anotaciones en un libro necrológico ${ }^{174}$, etc. En este sentido, hemos de llamar la atención sobre el especial interés de los asientos del Obituario 3 relativos a miembros de la familia real inhumados en San Isidoro, pese a contener algunos apuntes errores o presentar divergencias con respecto a las noticias relativas a los mismos personajes recogidas en otras fuentes ${ }^{175}$. Desaparecidos íntegramente varios de los epitafios, conservados otros fragmentariamente, conocemos su texto sólo a través de transcripciones tardías que, como hemos comprobado, no son absolutamente fiables. Por lo tanto, los sucintos asientos en el Obituario 3 referidos a figuras como la reina Elvira (esposa de Vermudo II), Zaida y las infantas Urraca, Elvira (hijas ambas de Fernando II) y Estefanía son hoy los testimonios más antiguos de su

en ellas.

${ }^{174}$ Tomemos como ejemplo los testimonios escritos referidos a la defunción de la reina Urraca, madre de Alfonso VII. La resolución del año de fallecimiento resulta más sencilla en las adiciones del obituario y del martirologio de la canónica $\left(E r a \mathrm{M}^{\mathrm{a}} \mathrm{C}^{\mathrm{a}} \mathrm{L} \mathrm{X}^{\mathrm{a}} \mathrm{IIII} \mathrm{I}^{\mathrm{a}}\right.$ ) que en los versos de uno de sus epitafios, en verso, transcrito por M. RISCO, Iglesia de León, p.151: "Hoc Urraca jacet pulcro Regina sepulchro, Regis Adefonsi filia quippe boni. Undecies centum decies sex quatuor annos. Martis mense gravi, cum moritur, numera". El epígrafe en prosa -también desaparecido- carecía, parece, de data: "H.R. Domna Urraca Regina, mater Imperatoris Alfonsi".

${ }^{175}$ Por lo que se refiere a la adscripción de mes y día, según N. HUYGHEBAERT, O.c., p. 36 , en un obituario la data exacta del fallecimiento es, pues, de importancia secundaria. Véase al respecto de esta cuestión el significativo ejemplo analizado por L. MARTíNEZ ÁNGEL, Sobre un posible error en la fecha de la muerte del obispo Sampiro de Astorga en los obituarios de la catedral de León, "Astorica", 19 (2000), pp. 245-250. 
¿DEL PERGAMINO A LA PIEDRA? ¿DE LA PIEDRA AL PERGAMINO?

fallecimiento que forman parte del patrimonio escrito isidoriano. El Obituario3 tendrá que ser considerado como fuente a partir de ahora en cualquier aproximación histórica tanto a las figuras anteriormente citadas, como a los reyes Vermudo II, Vermudo III, Sancho el Mayor de Navarra o Sancha (esposa de Fernando I).

En definitiva, tomando como base el patrimonio escrito superviviente, queda demostrada, para el periodo objeto de estudio, la complementariedad de las tres fuentes consideradas: diplomas, obituarios y epitafios, tanto en el contenido como en la finalidad de la comunicación que se establece. La comunidad isidoriana decide la materialización de una determinada noticia de carácter funerario en uno $\mathrm{u}$ otro objeto atendiendo a la duración que se pretende tenga el mensaje y a los destinatarios de la información. No se reproduce exactamente un mismo texto en soportes diferentes, no se traslada a la piedra un asiento obituario ni simultáneamente ni con notable posterioridad al momento del fallecimiento consignado. Como consecuencia, cualquier investigador que desee aproximarse con rigor a la historia de San Isidoro de León y de los personajes relacionados de algún modo con este centro eclesiástico de primer orden, forzosamente habrá de recurrir, para la obtención de información, a piedras y pergaminos. 